\title{
¿Puede la Institución Escolar contribuir en la construcción de sociedades más racionales? La Institución Escolar a la luz de la Teoría de la Acción Comunicativa
}

\author{
PAZ GIMENO LORENTE \\ Mec-Zaragoza
}

\begin{abstract}
SUMMARY.-The aim of this article is to answer the following question: can the school institution to collaborate to make our forthcoming societies the most rational and humanistic ones? First of all, it is argued that, if a school institution is able to get priority for its critical function, it can effectively contribute to improve the rationality of both the social and individual ways of life. For that to be possible, the school must organize its dynamics around the communicative rationality criteria. Second, it is marked that, in general, the school institution has a double nature, as well as, particularly, the school organization, showing the need ofr breaking the reductionist conceptions restricting the understading of the school phonomena when these are faced solely from an exclusive and particular wiewpoint; this double nature of the school relates with the two kinds of rationality technical and practical which pervade the school actions and functions. Third, the habermasian concept of communicative rationality is introduced as a norm reference for the life and dynamics of the school when its purpose is to contribute to reach a better rationality into society. All these arguments are embedded into the Critical Theory of Education.
\end{abstract}

\section{INTRODUCCIÓN}

En un principio puede parecer artificial establecer un enlace entre un modelo teórico-social, como la Teoría de la Acción Comunicativa de Habermas, y el ámbito institucional de la educación. Lejos de esto y aunque el propósito que guía a este autor reside en proporcionar una herramienta conceptual y teórica que permita comprender y analizar la vida social y las condiciones en que ésta se produce y mantiene -es decir, una teoría de la sociedad-, resulta muy esclarecedor para la Institución Escolar establecer las conexiones entre el análisis crítico del sistema social como totalidad y el subsistema educativo como institución social utilizando aquel marco teórico. Evidentemente, el carácter específico de la escuela, más próximo al mundo vital de una sociedad, hace preciso que este instrumento conceptual sea adaptado al contexto escolar.

A la pregunta acerca de si la Institución Escolar puede contribuir en la construcción de una sociedad más humana y racional, en el sentido aristotélico, se contesta en este artículo con el planteamiento constructivo y esperanzado del que parte Habermas en su 
Teoría de la Sociedad: la especie humana va incorporando progresivamente aquellos conocimientos que le son útiles para mejorar las condiciones de vida, al tiempo que desarrolla nuevas estrategias cognitivas que le permiten responder a las sucesivas cuestiones y problemas que se le plantean. Esta capacidad de aprender le permite evolucionar a través de sucesivas etapas de carácter cada vez más complejo. El estudio histórico de las formas de organización social proporciona argumentos para mantener este presupuesto sobre el progreso evolutivo. Pero la capacidad racional de la humanidad no avanza de forma espontánea. Es necesario que el individuo vaya incorporando sucesivamente nuevos aprendizajes que le permitan el ejercicio de su racionalidad de manera más compleja, atendiendo no sólo a los aspectos instrumentales de la razón, como adecuación de medios afines, sino también a los aspectos morales, en cuanto selección de los mejores fines para todos. En el desarrollo de los aprendizajes necesarios para que, primero como individuo y después como grupo social, el ser humano pueda actuar con un mayor nivel de racionalidad, la Institución Escolar puede jugar un importante papel. En este sentido se propone una determinada forma de entender las funciones que la escuela puede cumplir en la sociedad. Estas funciones quedan orientadas hacia el aprendizaje y ejercicio de la crítica, ya que este es el principal instrumento «racional» que posee la humanidad para controlar los afanes de dominio de unos individuos sobre otros. Afanes que convierten en irracional -en cuanto que no respetan los principios morales que regulan una convivencia en igualdad de libertades- las acciones y estructura de la sociedad.

Este artículo pretende, en primer lugar, señalar que una Institución Escolar que priorice sus funciones críticas, sí puede contribuir a mejorar los niveles de racionalidad de las formas de vida sociales e individuales. Para ello la propia escuela debe organizar sus dinámicas en torno a criterios de razón crítica, la cual adopta la forma de una razón comunicativa. En segundo lugar, se desea dejar constancia de la doble naturaleza de esta Institución Escolar, en general, y de las organizaciones escolares, en particular, señalando la necesidad de romper con aquellas visiones parciales y reduccionistas que limitan la comprensión de la escuela al afrontarla desde una sola perspectiva. Esta doble naturaleza apunta hacia los dos tipos de racionalidad que impregnan las funciones y acciones de la escuela: la razón instrumental y la razón práctica. En tercer lugar, se presenta el concepto de acción comunicativa habermasiano como un referente normativo de la vida de la escuela, cuando ésta se plantea el contribuir al logro de mayores cotas de racionalidad en la sociedad, señalando una posible tipología de las acciones que se llevan a cabo dentro de las organizaciones escolares. Esta tipología se propone como artificio metodológico con la pretensión de favorecer la comprensión de las dinámicas que se generan en la escuela indicando el modelo de racionalidad predominante en las acciones que allí se realizan. Todo este planteamiento queda situado en el marco de la Teoría Crítica de la Educación.

\section{JUSTIFICACIÓN DEL MARCO TEÓRICO-CRÍTICO PARA LA COMPRENSIÓN DE LA INSTITU- CIÓN ESCOLAR}

La principal justificación de que el marco analítico propuesto por Habermas puede servirnos para una mejor comprensión de la Institución Escolar, viene dada por la natu-

1. Los fundamentos de la Teoría Crítica de la Educación se hallan expuestos en: Gimeno Lorente, P. (1993), De la Teoría Crítica de la Sociedad a la Teoría Crítica de la Educación, tesis doctoral (inédita), U.N.E.D., Facultad de Educación. 
raleza específica de esta institución. Miedema (1987) considera que la Institución Escolar se ubica simbólicamente en la interrelación teórica de los conceptos de sistema y mundo de la vida.

Desde su origen como institución social la escuela realiza una doble tarea. Por una parte lleva a cabo la misión de enseñar a los jóvenes las técnicas para el ejercicio del trabajo, pero por otro se ocupa también de la transmisión ideológica, transmitiendo las concepciones sociales necesarias para mantener el orden establecido. Esta doble y permanente tarea la sitúa en un lugar de intersección entre la respuesta a las necesidades de supervivencia propias de un sistema social -transmisión de concepciones simbólicas y de técnicas de producción material- y la búsqueda de alternativas -a través del conocimiento- a las formas de vida sociales. Si estos cambios originados por los avances sociopolíticos que se derivan de nuevos modos de producción son rápidos y frecuentes, las respuestas creativas que se le piden a la escuela son mayores. Esta doble misión corresponde a la naturaleza dual de la escuela, lo que hace preciso también un análisis desde una doble perspectiva teórica. Así, la Institución Escolar puede ser entendida como «sistema» en cuanto que responde por su estructura y funcionalidad a las características de un sistema social, incardinado en un conjunto de orden superior, la sociedad en su totalidad. A este subsistema se le denomina «sistema educativo», teniendo como función prioritaria la conservación y mantenimiento del orden social. Igualmente puede ser comprendida como parte del «mundo de la vida» porque responde a la necesidad de transmisión de la sociedad de todos los esquemas interpretativos y de valores que configuran su mundo vital, posibilitando, si se prioriza esta posición, una función de cambio o crítica.

La naturaleza dual de la escuela precisa, para su comprensión, de un esquema analítico mixto que refleje esta dualidad. Por este motivo, el esquema de análisis que propone Habermas para comprender la sociedad y su tesis sobre la acción comunicativa entendida como núcleo reproductor del mundo simbólico social, parecen ser adecuados para llevar a cabo esta tarea comprensiva de la Institución Escolar. La aplicación de este esquema analítico social al mundo de la escuela precisa evidentemente de un ajuste, ya que en el ámbito escolar tienen un mayor peso las concepciones simbólicas, con sus connotaciones práctico-morales, que su contribución específica a la reproducción del sistema social. Por otra parte, desde la concepción educativa teórico-crítica en la que me sitúo, el carácter crítico que la escuela posee potencialmente adquiere mayor relevancia que el reproductor.

En la propia historia de la Institución Escolar se ve reflejada esta doble naturaleza. Su carácter simbólico se aprecia en que, a pesar de que en su origen no tenía un carácter institucional específico pues la tarea de la enseñanza era asumida por otras instituciones como la Iglesia o los gremios artesanales, la principal función educativa ha sido siempre la de asegurar la reproducción de los contenidos simbólicos de la sociedad que constituyen su mundo de la vida colectivo, como la cultura, la concepción de sociedad y de sus formas de vida, y los modelos ideales de individuo. En la necesidad de que la escuela se hiciera cargo de la transmisión a las nuevas generaciones de los conocimientos precisos para afrontar sus funciones productivas, reside el motivo de su institucionalización. En esta transmisión simbólica se contemplaban tanto los contenidos del conocimiento precisos para afrontar sus funciones productivas, reside el motivo de su institucionalización. En esta transmisión simbólica se contemplaban tanto los contenidos del conocimiento adquirido evolutivamente, como los valores, sociales e individuales, que aquéllos lleva- 
ban aparejados. La Iglesia al hacerse cargo de esta tarea insistía más en estos valores que en la propia transmisión del saber cultural, especialmente en la formación dirigida a las clases menos favorecidas. Al asumir el Estado esta tarea, en el siglo XIX, comienzan a primar los valores laicos (políticos) y los conocimientos instrumentales que posibiliten la formación de ciudadanos más cualificados para la producción.

En el momento actual, donde la diferenciación de las esferas relativas a la ciencia, la moral y la estética ha originado unos subsistemas especializados en diferentes saberes, la educación queda institucionalizada y es denominada comúnmente como «sistema educativo» o «sistema escolar». Se diferencia de otras instituciones que también se enmarcan en el mundo de la vida social al asumir funciones propias, como la anteriormente citada, y formas de acción específicas. Esta diferenciación funcional mantiene su naturaleza simbólica, considerándose depositaria de la herencia cultural de la sociedad y encargada de transmitir esta herencia a las nuevas generaciones. Pero la cultura, como señala Habermas, no es el único componente del mundo de la vida social que reproduce la escuela. También forman parte de este mundo vital la sociedad y la personalidad. Por ello, los procesos de transmisión que lleva a cabo la escuela incluyen también formas de vida, valores sociales e individuales, e incluso modelos de referencia sobre cómo debe ser un individuo «educado». En estos procesos juega un importante papel la valoración social de las funciones productivas del individuo, por lo que la Institución Escolar asume como tarea prioritaria la cualificación instrumental de los alumnos, con la vista puesta en el desempeño futuro de una profesión u ocupación laboral.

A la par, esta misma reproducción simbólica contribuye a la reproducción funcional de la sociedad. Ya hemos señalado la estrecha conexión que se da entre los contenidos de conocimiento y los valores sociales que éstos llevan aparejados: la transmisión cultural asegura el cumplimiento, cada vez más complejo, de las funciones de reproducción material de la sociedad, por lo que la cualificación cultural de las nuevas generaciones se hace progresivamente más sofisticada. Asimismo la transmisión simbólica de unas formas de vida social, es decir, la transmisión (explícita u oculta) de una serie de valores acerca de cómo debe ser la sociedad y de criterios de actuación individual, ${ }^{3}$ permite el mantenimiento del propio sistema social. De esta forma la reproducción del mundo de la vida, como función que desempeña la Institución Escolar, contribuye al mismo tiempo a la integración sistemática de la sociedad, en cuanto que le sirve de legitimación y soporte de sentido.

2. Estos valores sociales son los que favorecen la reproducción estructural de la sociedad con sus injusticias y situaciones de dominio, al tiempo que, dialécticamente, permiten la transformación de estas situaciones. Su funcionalidad depende de cuáles sean estos valores dominantes.

3. Estos valores responden a los otros dos componentes del mundo de la vida -sociedad y personalidad- a cuyo mantenimiento contribuye la escuela como sistema mediante procesos de socialización y de formación de la identidad.

4. Esta naturaleza mixta de la Institución Escolar ha de alertarnos respecto al reduccionismo y consecuente debilidad -quizá teñida de ideología- de aquellos estudios e investigaciones sobre la misma, donde prevalecen las concepciones e instrumentos metodológicos de carácter sistémico, e igualmente en el caso de los estudios exclusivamente fenomenológicos sobre esta institución. La complejidad de una organización escolar así como la doble naturaleza de sus funciones, deriva en buena lógica, en un planteamiento de análisis dialéctico, donde se integren los métodos empíricos (más adecuados en la comprensión de los componentes sistémicos) con los hermenéuticos (ade- 
Así pues, la Institución Escolar realiza una doble función (Schaller, 1987, pp. 246249): la función de reproducción del sistema a través de la transmisión cultural y los valores sociales que aquélla lleva aparejados (función sistémica), y la función crítica, al tener capacidad para replantear las concepciones sociales acerca de la sociedad y el conocimiento y por tanto, para transformar los significados colectivos y los esquemas interpretativos de la sociedad (función simbólica). Miedema (1987, p. 753) pone el acento en este potencial crítico de la escuela al considerarla como una institución que se sitúa en los márgenes del sistema y del mundo de la vida, lo que permite que en ella se puedan aprender nuevas conductas o valores alternativos como el feminismo, el ecologismo, el pacifismo, actitudes de solidaridad, de aceptación multicultural, etc.

Este potencial crítico de la escuela es el que deseo subrayar al plantear las funciones que lleva a cabo una Institución Escolar entendida desde una perspectiva teórico-crítica. Esto me lleva a considerar la acción comunicativa como referente para la acción educativa al responder en su dinámica a un modelo de racionalidad comunicativa con componentes éticos, lo que permite la reconstrucción crítica de aquellas situaciones sociales contaminadas por mecanismos de dominio, fruto de la imposición de los intereses particulares de unos pocos.

\section{LA TEORÍA CRÍtiCA DE LA SOCIEDAD DE HABERMAS Y LA INSTITUCIÓN EsCOLAR}

Habermas habla de educación en pocas ocasiones, pero alude con mayor frecuencia al término «aprendizaje». Este concepto queda integrado en su teoría de la evolución onto y filogenética y hace referencia a los aprendizajes sociales como instrumento de desarrollo evolutivo, desempeñando un importante papel el aprendizaje de los propios individuos que constituyen las sociedades. Es decir, el progreso de la especie humana -dentro del marco teórico de los estadios evolutivos señalados en el estructuralismo genético de Piaget, la teoría de los estadios morales de Kolhberg y la teoría de los estadios de desarrollo del ego de Loevinger-, se produce por la capacidad de los individuos integrantes de sucesivas generaciones (individual y colectivamente) para aprender nuevos comportamientos, que de forma paulatina se van incorporando al código genético y sociocultural de la especie.

Habermas confía en la capacidad humana para lograr un grado de autonomía que le permita vivir con mayor racionalidad en sociedades más humanizadas, considerando

cuados en la comprensión de objetos entroncados específicamente con el mundo de la vida de los participantes), si bien subordinando los primeros a los segundos, y por último pasando a ambos por la criba del método crítico-ideológico, que trae al plano analítico todos los componentes sociales (intereses, mecanismos de dominación, conflictos...) que intervienen en cualquier dinámica escolar que se aborde. Esta perspectiva crítico-ideológica será quien plantee criterios éticos orientados a la emancipación, como contribución al análisis y posterior intervención.

5. A raíz de los movimientos de protesta de los estudiantes, en los años 60, Habermas escribe algunos libros y artículos referidos a educación. Véase: Habermas (1969); en colaboración con otros autores: (1961), (1975); y Habermas (1978b, pp. 351-359). A lo largo de sus disertaciones aparecen también algunos comentarios referidos a la educación, pero no excesivamente extensos (en: Habermas, 1987a, vol. 2, pp. 520-527).

6. Véanse: Habermas (1985 pp. 85-11); y Hernández Pedrero, (1988). 
que, mediante el aprendizaje de nuevas formas de comportamiento y de pensamiento más racionales, éstas se pueden incorporar evolutivamente a las estructuras cognitivas humanas. Esta confianza en el progreso del hombre le hace detenerse en la función de los sistemas escolares como forma institucional de asegurar el aprendizaje de la racionalidad.

Aunque Habermas no haga especial hincapié en el análisis de la esfera educativa institucional, su tesis respecto a los procesos de reproducción del mundo simbólico de las sociedades facilita la explicación de los fenómenos de la misma naturaleza que se producen en la Institución Escolar. Así, el marco teórico de análisis que propone para la comprensión de cómo se reproducen las sociedades, a partir de los fenómenos simbólicos que las configuran y dan consistencia, es válido para entender cuáles son las funciones que desempeña la Institución Escolar en el contexto social. Por otra parte, la consideración de una especie humana capacitada para el aprendizaje induce una concepción de la escuela como instrumento crítico que puede favorecer la existencia de futuras sociedades más racionales. Esta esperanza no es fruto de la «falsa conciencia» de considerar la educación como actuación humana ajena a la urdimbre social de poder donde se lleva a cabo. En realidad la escuela suele ir detrás de la sociedad y con frecuencia acentúa sus limitaciones reproduciendo, a través de los contenidos culturales, sus estructuras sociales de dominio, pero también es cierto que la Institución Escolar posee un potencial crítico que le posibilita para enseñar a las nuevas generaciones formas alternativas de pensamiento y de acción. En este potencial crítico es donde pone el acento una teoría educativa crítica.

Habermas parte del principio de que las sociedades se mantienen en función de su capacidad para asegurar sus anclajes en el mundo de la vida colectivo, a través de acciones dirigidas al entendimiento, es decir, incluso los procesos de reproducción material que permiten su mantenimiento estructural se asientan sobre fenómenos de naturaleza simbólica mediados por el lenguaje (comprensión de la naturaleza y de las relaciones del hombre con ella). La escuela, en su tarea de reproducción de los esquemas culturales, sociales y de comprensión del individuo que permiten la supervivencia de la sociedad, utiliza el lenguaje como principal instrumento: Habermas centra las funciones de reproducción simbólica en el concepto de acción comunicativa, término que, además de ser un constructo teórico, sirve como orientación racional de nuestras sociedades. Siguiendo en la línea de paralelismo establecida con la escuela, ésta se apoya precisamente en la capacidad comunicativa de sus miembros, es decir, sus fenómenos se producen sobre la base de las interacciones comunicativas de sus participantes. Esto hace que la acción comunicativa nos sirva como indicador para evaluar el grado de racionalidad y humanización de una sociedad, desde la perspectiva teórico-crítica, y como referente de la calidad de una organización escolar, quedando definido de la forma siguiente: la mayor proximidad al establecimiento de una organización escolar donde predominen las acciones comunicativas posibilitará que en su dinámica y funcionamiento se alcancen mayores cotas de racionalidad y, por tanto, de calidad educativa.

Pero la Teoría de la Acción Comunicativa tiene también presente que las sociedades postindustriales, debido a la creciente complejidad que han alcanzado, poseen mecanismos funcionales que escapan a la conciencia de los miembros de la sociedad y que contribuyen también al mantenimiento de la misma. Del pensamiento de Durkheim sobre la «división del trabajo», a partir del cual explica los procesos de diferenciación estructural 
de los sistemas sociales, Habermas elabora la tesis de la conexión empírica existente entre las etapas de diferenciación sistémica y las formas de integración social. Considera -y ésta es la tesis de Habermas- que el análisis de estas relaciones sólo es posible «si se distingue entre los mecanismos de coordinación de la acción que armonizan entre sí las orientaciones de acción de los participantes y aquellos otros mecanismos que a través de un entrelazamiento funcional de las consecuencias agregadas de la acción estabilizan plexos de acción no pretendidos» (Habermas, 1987a, vol. 2, p. 167). Es decir, los procesos de integración social que aseguran el nexo y constituyen la trama sobre la que se asienta y reproduce la sociedad, están constituidos los procesos de naturaleza diferente. Unos, de carácter simbólico, donde las acciones de los miembros de la sociedad quedan asegurados a través de procesos comunicativos encaminados al logro de acuerdos, y otros, de naturaleza funcional y no consciente para los miembros de la sociedad, que se regulan a través de procesos de integración sistemática.

Esta diferenciación de los procesos de integración social lleva a Habermas a proponer un análisis de los procesos de reproducción social a partir de un esquema integrado por dos líneas metodológicas diferentes. Por una parte adopta un marco categórico sistémico, revisado (desde Parsons a Luckmann), y por otra, utiliza el concepto fenomenológico de «mundo de la vida» de Husserl (en la versión de Schutz y Luckmann), entendiendo este análisis bajo la perspectiva de una Teoría de la Acción Comunicativa. Desde la concepción dual de «sistema» y «mundo de la vida» pretende superar las limitaciones de una concepción de la sociedad únicamente entendida como mundo de la vida que se reproduce a partir de las acciones orientadas al entendimiento de sus miembros. La simultaneidad de la consideración de los conceptos de «sistema» y «mundo de la vida» se fundamenta en una teoría de la evolución social que distingue entre racionalización del mundo de la vida y aumento de la complejidad de los sistemas sociales. Habermas introduce, utilizando el concepto de cosificación de Lukacs revisado por Adorno y Horkheimer, una concepción de los actos de entendimiento que permite retomar estos fenómenos de alienación y falsa conciencia y sacarlos a la luz «en» y «a través» de los procesos de comunicación. Esto es, una sociedad que quiera disminuir los efectos alienantes que sobre sus miembros ejercen los procesos inconscientes de integración sistémica, deberá, a través de la ampliación institucional de los espacios públicos abiertos a la comunicación, hacer conscientes tales procesos para impedir la colonización de éstos sobre su mundo de la vida colectivo.

$\mathrm{La}$ tarea de devolver a la conciencia de los individuos aquellos procesos de integración social que han quedado asegurados en el plexo de las reproducciones sistémicas en vez de en las simbólico-normativas, y que deberían estar basadas en acuerdos intersubjetivos, es también responsabilidad de una Institución Escolar, entendida desde la filosofía humanística que configura la Teoría Crítica. Pero, para ello, los miembros adultos de esta Institución precisan, en primer lugar, hacerse conscientes, mediante procesos de reflexión intersubjetiva, de estos fenómenos de cosificación y sus causas. En segundo lugar, su tarea consistirá en introducir como objetivo prioritario del currículo el desarrollo, en los alumnos, de aquellas competencias comunicativas y discursivas necesarias para poder tomar conciencia crítica sobre estos fenómenos reificadores y llegar a acuerdos intersubjetivos libres de dominio.

Pero antes de pasar a exponer el esquema analítico que propone Habermas, describiré brevemente los conceptos básicos sobre los que fundamenta su esquema. 
Dentro del paradigma comunicativo por el que ha optado, Habermas toma de la fenomenología husserliana el concepto de «mundo de la vida»? Utiliza este concepto teniendo como horizonte el ámbito de la comunicación humana, refiriéndose a éste como el contexto vital sobre el que se asienta la comunicación humana, refiriéndose a éste como el contexto vital sobre el que se asienta la comunicación intersubjetiva. De este horizonte deduce las funciones que la acción comunicativa desempeña en el mantenimiento de un mundo de la vida estructuralmente diferenciado. Define el concepto en términos de pragmática formal como:

«...el lugar trascendental en que el hablante y el oyente se salen al encuentro; en que puede plantearse reciprocamente la pretensión de que sus emisiones concuerden con el mundo (con el mundo objetivo, con el mundo subjetivo y con el mundo social); y en que pueden criticar y exhibir los fundamentos de esas pretensiones de validez, resolver sus disentimientos y llegar a un acuerdo» (Habermas, 1987a, vol. 2, p. 179),

estableciendo una clara diferencia entre los conceptos de «mundo» como «aquello sobre que los participantes en la interacción se entienden entre sí» $\mathrm{y}$ «mundo de la vida» como «aquello desde donde inician y discuten sus operaciones interpretativas» (Habermas, 1989, p. 489).

Los componentes estructurales que componen el mundo de la vida son: la cultura, la sociedad y la personalidad. Habermas los describe de la siguiente manera:

«Cultura es el acervo de saber, en que los participantes en la comunicación se abastecen de interpretaciones para entenderse sobre algo en el mundo».

«Llamo sociedad a las ordenaciones legítimas a través de las cuales los participantes en la interacción regulan sus pertenencias a grupos sociales, asegurando con ello la solidaridad».

«Y por personalidad entiendo las competencias que convierten a un sujeto en capaz de lenguaje y de acción, esto es, que le capacitan para tomar parte en procesos de entendimiento y para afirmar en ellos su propia identidad» (Habermas, 1987a, vol. 2, p. 196).

Habermas señala, en estas definiciones, la conexión interna entre las estructuras del mundo de la vida y las estructuras de la imagen lingüística del mundo, es decir, que el campo semántico de los contenidos simbólicos se construye sobre acciones comunicativas. El lenguaje y la cultura son elementos constitutivos del mundo de la vida mismo. Esto coloca a los participantes en las interacciones orientadas al entendimiento en una situación de semitrascendencia, ya que al realizar un acto de habla están tan dentro de su lenguaje que no lo pueden poner frente a sí, objetivándolo, para cuestionar su validez. Esta condición forma parte de ese acervo de saber que los participantes dejan a su espal$\mathrm{da}, \mathrm{y}$ por tanto es aproblemático, constituyendo el horizonte sobre el que se mueven los agentes comunicativos. Este es su mundo de la vida. Pero antes de continuar será preciso clarificar cual es el concepto de comunicación que Habermas emplea.

Habermas considera como acciones comunicativas a aquellas acciones en las que los participantes mantienen una actitud orientada al entendimiento, es decir, orientada al lo-

7. Este concepto lo extrae de la versión revisada de Schutz y Luckmann. 
gro de un acuerdo intersubjetivo por la vía comunicativa y con una base racional. En estas acciones los participantes no se coordinan a través de un cálculo egocéntrico de resultados sino mediante actos de entendimiento. No buscan primariamente el éxito individual en la acción, como sucede en las acciones estratégicas, sino que por el contrario persiguen sus fines individuales bajo la condición de que sus respectivos planes puedan armonizarse entre sí sobre la base de una definición compartida de la situación. Por ello, los procesos de negociación tienen gran importancia en la acción comunicativa (Habermas, 1987a, vol. 1, pp. 366-367).

En esta concepción de la acción comunicativa conviene distinguir varias condiciones que Habermas considera determinantes para definir una acción como verdaderamente comunicativa. Algunas de ellas son previas a la propia acción comunicativa, a) y otras son internas a la misma, b).

a) Como condición previa indica, en primer lugar, que tales acciones deben llevarse a cabo entre sujetos capaces de lenguaje y acción. En segundo lugar, deben darse unas condiciones de simetría entre los participantes, es decir, ambos deben estar en las mismas condiciones para establecer la interacción y, en tercer lugar, ésta debe llevarse a cabo sin ningún tipo de coacciones, es decir, la interacción debe estar libre de dominio.

b) Como condiciones internas, señala:

- En primer lugar, su condición pragmática al ser acciones orientadas al entendimiento. Este tipo de acciones están basadas en el concepto de acción social de Weber y en la tipología que este autor establece para justificar sus tesis respecto a los procesos de racionalización social. A partir de la clasificación weberiana «no oficial» en la que se distinguen las acciones sociales según dos orientaciones básicas que son «la coordinación por tramas de intereses y la coordinación por acuerdo normativo», Habermas establece su propio modelo considerando tres tipos de acción: instrumental, estratégica y comunicativa. Esta última, la acción comunicativa, contempla el espacio de intersubjetividad como generador de sentido, algo que no se tiene en cuenta en los otros dos tipos de acciones. Por otra parte, esta intersubjetividad puede ser conocida empíricamente al ser fruto de una acción social, esto es, llevada a cabo por dos o más actores sociales, constituyendo la vertiente empírica de este concepto comunicativo.

- En segundo lugar, las acciones comunicativas están basadas en actos de habla ilocucionarios. Apoyándose en la clasificación de los actos de habla de Austin (1982) sobre los efectos ilocucionarios y perlocucionarios de un acto de habla, Habermas señala que las acciones comunicativas precisan de actos ilocucionarios, es decir, el hablante realiza una acción diciendo algo (afirma, manda, promete...) y su intención será que el oyente entienda con claridad y sin equívocos lo que él hace cuando habla. Sus fines también deben ser ilocucionarios. Por el contrario, en los actos de habla perlocucionarios el hablante lo que busca es causar un efecto en el oyente, es decir, causar algo mediante lo que se hace cuando dice algo. Sus fines son estratégicos y sus propósitos sólo pueden ser conocidos por el oyente averiguando la intención del hablante.

Para que una acción sea comunicativa es preciso que tanto el oyente como el hablante estén utilizando proposiciones con efectos ilocucionarios de manera que ambos comprendan claramente lo que se hace cuando se habla. La acción comunicativa se distingue de la estratégica en que todos los participantes persiguen sin reservas fines ilocucionarios con el propósito de llegar a un acuerdo que sirva de base para sentar los planes de una acción futura coordinada (Habermas, 1987 a, vol. 1, pp. 370 y ss.). 
- En tercer lugar, y entramos ya en el terreno de los discursos, las acciones comunicativas deben tener una base racional. Esto significa que las proposiciones con efecto ilocucionario que se emplean en la interacción comunicativa, han de satisfacer determinadas pretensiones de validez, las cuales han de poder ser sometidas a crítica. Las tres pretensiones de validez de una acción comunicativa son: la verdad, la adecuación normativa, y la sinceridad. Si el oyente duda de alguna de estas tres condiciones habrá de cuestionarla y el hablante deberá satisfacerla mediante argumentaciones. Sólo así podrá ser considerado de carácter racional el consenso alcanzado.

- En cuarto y último lugar, los consensos alcanzados a través de acciones comunicativas han de responder a intereses generales, es decir, a través de la negociación se alcanzarán acuerdos donde los intereses particulares queden conciliados. Además, en las acciones derivadas de los mismos, cualquier participante virtual en esa interacción deberá poder sentir reconocido su interés. Así pues, los acuerdos deben responder a los intereses de la generalidad. Esta pretensión de universalidad tiene su origen en el «imperativo categórico» kantiano, pero Habermas lo plantea como fruto de una determinación dialógica, intersubjetiva, en lugar de responder a la posición monológica y subjetiva original.

Regresando de nuevo al concepto de mundo de la vida empleado por Habermas, éste toma de la versión de Luckmann y Schutz algunos aspectos significativos. En primer lugar, el mundo de la vida se halla conectado con tres mundos que sirven de base para que los individuos establezcan definiciones comunes de la situación. El sujeto se puede relacionar con algo que tiene lugar o se puede producir en el mundo objetivo ("como totalidad de las entidades sobre las que son posibles enunciados»); con algo que es reconocido como propio de un mundo social y que es compartido por todos los miembros de una comunidad ( como totalidad de las relaciones interpersonales legítimamente reguladas»); o con algo que los actores atribuyen al mundo subjetivo de los hablantes y sobre el que sólo el hablante tiene un acceso libre («como totalidad de las propias vivencias a las que cada uno tiene un acceso privilegiado y que el hablante puede manifestar verazmente ante un público») (Habermas, 1987a, vol. 2, p. 171). Estas relaciones fundamentan, a su vez, las pretensiones de validez que debe satisfacer un acto de habla comunicativo.

Pero aunque se plantee esta distinción las acciones comunicativas están insertas, al mismo tiempo, en diversas relaciones con el mundo.

«La acción comunicativa se basa en un proceso cooperativo de interpretación en que los participantes de refieren simultáneamente a algo en el mundo objetivo, en el mundo social y en el mundo subjetivo aun cuando en su manifestación sólo subrayen temáticamente uno de estos tres componentes» (Habermas, 1987a, p. 171).

Pero existe una dimensión intersubjetiva que la Fenomenología olvida desde Husserl ${ }^{8}$ y que Habermas recupera al situarse en un paradigma comunicativo. Desde esta perspectiva teórica considera al mundo de la vida como un contexto mediato que, aunque accesible al principio, no es objeto temático, constituyendo una red familiar intuitivamente

8. Husserl en sus Meditaciones cartesianas, centra el concepto de mundo de la vida en el sujeto como individuo («ego como subjetividad trascendental»). 
presente y transparente pero inabarcable, que dota de presuposiciones al acto comunicativo y permite que la emisión sea válida y tenga sentido. Esta certeza es debida a un $a$ priori social inscrito en la intersubjetividad del entendimiento lingüístico. La comunalidad de este mundo de la vida no puede ser cuestionada como si se tratase simplemente de un conocimiento compartido; lo más extremo que puede suceder es que se venga abajo. Solamente cuando éste se torna problemático, puede quedar convertido en objeto temático de discusión para quienes lo comparten, ya que «las estructuras del mundo de la vida fijan las formas de intersubjetividad del entendimiento posible» (Habermas, 1987a, vol. 2, p. 179). La única forma de transcender los límites de esta base común de interpretaciones es la reflexión teórica, pero para que ésta surja es necesario experimentar la vivencia de que algunas de estas interpretaciones resultan insuficientes para dar respuesta a nuevas situaciones.

En consecuencia, las funciones que cumplen las acciones orientadas al entendimiento en la reproducción del mundo de la vida son las siguientes:

«Bajo el aspecto funcional de entendimiento, la acción comunicativa sirve a la tradición y a la renovación del saber cultural; bajo el aspecto de coordinación de la acción, sirve a la integración social y a la creación de solidaridad; y bajo el aspecto de socialización, finalmente sirve a la formación de identidades personales» (Habermas, 1987a, vol. 2, p. 196).

A estos procesos de reproducción cultural, integración social y socialización, les corresponden los componentes estructurales del mundo de la vida: cultura, sociedad y personalidad.

Habermas retoma estas categorías y propone su integración en un marco analítico (véase fig. 2) donde sitúa las funciones que la acción comunicativa cumple en los procesos de reproducción del mundo de la vida. En este esquema de análisis, combina la perspectiva sistémica con la fenomenológica, interrelacionando las categorías del mundo de la vida social (cultura, sociedad y personalidad) con las de los procesos de integración sistémica referidos al mundo simbólico (reproducción cultural, integración social y socialización). En la interrelación de ambas perspectivas se producen una serie de fenómenos que contribuyen al mantenimiento de los componentes estructurales del mundo de la vida.

La reproducción material de la sociedad, señala Habermas, se cumple a través de la actividad racional orientada a fines -como la definía Weber-, si bien ésta se asienta como saber técnico (tecne) en un conocimiento que precisa de los fenómenos simbólicos para su traspaso de unas generaciones a otras. Esta es una de las tareas que lleva a cabo la escuela al traspasar la tradición cultural, con su acervo de conocimientos técnicos acumulados, de una generación a la siguiente.

Por otra parte al mundo simbólico social le resulta imprescindible un sustrato material que posibilite su existencia. Este sustrato, a su vez, forma parte de los significados y valores del mundo de la vida, ya que el saber teórico y técnico, con el que damos respuesta a nuestras necesidades materiales, forma parte de nuestra urdimbre interpretativa del mundo en general. Por este motivo la Institución Escolar responde a la doble funcionalidad de contribuir a la conservación del mundo simbólico social -transmitiendo significados, valores, normas y saber práctico (teórico y preteórico)- y al mantenimiento de las estructuras materiales, transmitiendo intergeneracionalmente el saber teórico y técnico acumulado. 
Mundo de la vida

\begin{tabular}{|c|c|c|c|}
\hline $\begin{array}{l}\text { Proceso de } \\
\text { reproducción }\end{array}$ & Cultura & Sociedad & Personalidad \\
\hline Reproducción cultural & $\begin{array}{l}\text { Esquemas de } \\
\text { interpretación } \\
\text { susceptibles de } \\
\text { consenso (saber } \\
\text { válido) }\end{array}$ & Legitimación & $\begin{array}{l}\text { Patrones de } \\
\text { comporta- } \\
\text { miento efi- } \\
\text { caces en el } \\
\text { proceso de } \\
\text { formación }\end{array}$ \\
\hline Integración social & Obligaciones & $\begin{array}{l}\text { Relaciones } \\
\text { interpersona- } \\
\text { les legítima- } \\
\text { mente regu- } \\
\text { ladas }\end{array}$ & $\begin{array}{l}\text { Pertenencia } \\
\text { a grupos }\end{array}$ \\
\hline Socialización & Interpretaciones & $\begin{array}{l}\text { Motivacion } \\
\text { es para ac- } \\
\text { tuar de con- } \\
\text { formidad } \\
\text { con las nor- } \\
\text { mas }\end{array}$ & $\begin{array}{l}\text { Capacidad } \\
\text { es de inte- } \\
\text { racción } \\
\text { («identidad } \\
\text { personal») }\end{array}$ \\
\hline
\end{tabular}

Figura 2. Aportaciones de los procesos de reproducción al mantenimiento de los componentes estructurales del mundo de la vida (Habermas, 1987a, vol. 2, p. 202).

Los procesos sistémicos que contribuyen al mantenimiento simbólico de la sociedad, Habermas los aclara de la siguiente forma:

- La reproducción cultural del mundo de la vida se encarga de asegurar la continuidad de las tradiciones y de proporcionar una coherencia al saber, que facilite la comunicación cotidiana. Esta coherencia tiene su medida en la racionalidad del saber. Sus perturbaciones se manifiestan en una pérdida de sentido, originando crisis de motivación y legitimación.

- La integración social del mundo de la vida se encarga de que las acciones queden coordinadas a través de relaciones interpersonales legítimamente reguladas y de contribuir a la necesaria identidad de los grupos, que les permita desarrollar prácticas comunicativas cotidianas. Estos procesos tienen su medida en el grado de solidaridad de sus miembros. Cuando éstos se ven alterados, se originan fenómenos sociales de anomía, así como los lógicos conflictos derivados de aquéllos.

- La socialización de los miembros de un mundo de la vida, se encarga de asegurar a las nuevas generaciones la adquisición de capacidades para la acción, así como de sin- 
tonizar las formas de vida individuales con las colectivas. Estos procesos tienen su medida en la capacidad de las personas para responder con autonomía de sus acciones. Las perturbaciones en las mismas se manifiestan como psicopatologías y fenómenos de alienación.

Las aportaciones que los diferentes procesos de reproducción realizan a los distintos componentes estructurales del mundo de la vida son los siguientes:

- Si la cultura suministra el saber válido suficiente como para que se puedan establecer acciones comunicativas cotidianas, lo que los procesos de reproducción cultural aportan a los otros dos componentes del mundo de la vida son las legitimaciones para las instituciones sociales existentes y los patrones de comportamiento eficaces en los procesos de formación individual para que las nuevas generaciones adquieran competencias generales para la acción. La aportación que estos procesos de reproducción cultural llevan a cabo tiene un gran interés tanto para la legitimación de la escuela, en cuanto institución social, como para los procesos educativos individuales.

- Si los miembros de una sociedad se hallan suficientemente integrados, la contribución de estos procesos de integración al mantenimiento de los restantes componentes consiste en favorecer la pertenencia de los individuos a grupos, que se hallan legítimamente regulados, y en generar vínculos morales $u$ obligaciones en los individuos.

- Si los sistemas de personalidad han logrado una identidad sólida que les permite dominar las situaciones habituales de su mundo de la vida, la contribución de los procesos de socialización al mantenimiento de los otros componentes consiste en proporcionar las interpretaciones que los individuos elaboran y las motivaciones para actuar conforme a las normas (Habermas, 1987a, vol. 2, pp. 201-202).

Sobre esta base Habermas especifica las funciones que la acción comunicativa cumple dentro de estos fenómenos de reproducción, considerando prioritarias (véase fig. 3):

- El mantenimiento de la tradición, el ejercicio de la crítica, la adquisición del saber cultural.

- La coordinación de las acciones a través del reconocimiento de pretensiones de validez.

- La formación de la identidad individual.

Así pues Habermas define, en su esquema analítico, las funciones que desempeña la acción comunicativa en su contribución al mantenimiento del orden normativo social.

Como la Institución Escolar tiene una naturaleza básicamente simbólica, el medio a través del cual debería desempeñar sus tareas es -en el marco de la Teoría Crítica de la Educación- la acción comunicativa. Esta se convierte en un referente normativo de las dinámicas de la escuela, considerándola como medio prioritario sobre el cual debe desarrollarse la vida de las organizaciones escolares. Teniendo en cuenta la naturaleza mixta de la escuela, por una parte reproductora y por otra potencialmente crítica, la acción comunicativa permite señalar unas funciones específicas de la Institución Escolar encaminadas a la reproducción simbólica del mundo de la vida social, pero desde una posición crítica que potencie procesos de innovación y cambio, en primer lugar escolares y en su proyección futura sociales. 


\begin{tabular}{|c|c|c|c|}
\hline $\begin{array}{l}\text { Procesos de } \\
\text { reproducción }\end{array}$ & Cultura & Sociedad & Personalidad \\
\hline Reproducción cultural & $\begin{array}{l}\text { Tradición críti- } \\
\text { ca, adquisición } \\
\text { de saber cultu- } \\
\text { ral }\end{array}$ & $\begin{array}{l}\text { Renovación del } \\
\text { saber legitimador }\end{array}$ & $\begin{array}{l}\text { Reproducción } \\
\text { del saber eficaz } \\
\text { en los procesos } \\
\text { de formación }\end{array}$ \\
\hline Integración social & $\begin{array}{l}\text { Inmunización } \\
\text { de un núcleo de } \\
\text { orientaciones } \\
\text { valorativas }\end{array}$ & $\begin{array}{l}\text { Coordinación de } \\
\text { las acciones a tra- } \\
\text { vés del reconoci- } \\
\text { miento de } \\
\text { pretensiones de } \\
\text { validez }\end{array}$ & $\begin{array}{l}\text { Reproducción } \\
\text { de los patrones } \\
\text { de pertenencia } \\
\text { social }\end{array}$ \\
\hline Socialización & Enculturación & $\begin{array}{l}\text { Internalización de } \\
\text { valores }\end{array}$ & $\begin{array}{l}\text { Formación de } \\
\text { la identidad in- } \\
\text { dividual }\end{array}$ \\
\hline
\end{tabular}

Figura 3. Funciones de reproducción que cumple la acción orientada al entendimiento (Habermas, 1987a, vol. 2, p. 204).

Sobre este planteamiento, y desde la perspectiva de la Teoría Crítica de la Educación, se podrían considerar las siguientes funciones básicas para una Institución Escolar de talante crítico:

1. Como contribución al mantenimiento de la cultura: transmisión de la tradición cultural a través de la enseñanza del saber acumulado históricamente. Como movimiento de renovación y cambio: incorporación de contenidos críticos en el currículo (historia del movimiento obrero, del feminismo, ecologismo, conocimiento del mundo de las drogas y sus consecuencias, valoración y difusión de la cultura de minorías marginadas, etc.).

2. Como contribución a los procesos de integración de la sociedad y a la socialización de los individuos: enseñanza de los modos de comunicación necesarios para poder coordinar las acciones de unos individuos con otros y asegurar el mantenimiento de un orden social. Como movimiento crítico: enseñanza del procedimiento crítico a las nuevas generaciones, capacitándoles comunicativamente para poder cuestionar las tres pretensiones de validez que se plantean en una acción comunicativa (verdad, adecuación normativa, veracidad).

9. El término «competencias comunicativas» contempla las competencias cognitivas, lingüísticas, interactivas y morales necesarias para el establecimiento de un proceso de comunicación con otros. 
3. Como contribución al desarrollo individual: colaboración en la formación de su identidad a través del reconocimiento de expectativas mutuas (entre profesores y alumnos, entre alumnos...). Como crítica: contribución a la emancipación del individuo a través del desarrollo de su autonomía y de un pensamiento propio y crítico que le permita detectar los mecanismos de dominio sociales e individuales y luchar contra ellos.

Estas tres funciones prioritarias pueden ser asumidas por una Institución Escolar que coloca las acciones comunicativas en un lugar prioritario, introduciendo de esta forma en las organizaciones escolares un modelo de racionalidad comunicativa en cuya base se halla la crítica. Pero sería erróneo considerar que en el seno de esta institución sólo son precisas acciones de carácter comunicativo. Una cosa es considerar que la acción comunicativa debe constituirse en referente y orientación de la vida escolar, incluidas aquellas acciones que como las docentes están encaminadas a la transmisión cultural y por tanto deben impregnar, indirectamente, las acciones instructivas o de gestión de los centros escolares, otra pretensión, inadecuada completamente, sería la de intentar definir la relación educativa o el funcionamiento genérico de una escuela únicamente sobre acciones propiamente comunicativas en el sentido habermasiano. No es ésta mi intención. La naturaleza mixta de la Institución Escolar convierte a ésta en una institución compleja que precisa de diversas formas de actuación por parte de sus miembros. Eso sí, en la perspectiva teórico-crítica que aquí se propone, considero que el tipo de acción comunicativa debe constituir siempre el referente de logro, unas veces en forma directa e inmediatamente y otras de manera proyectiva en el futuro de los alumnos. En una utopía no declarada pero sí implícita, el ideal sería una organización escolar que estuviera regida prioritariamente por criterios de racionalidad comunicativa y no de racionalidad instrumental.

Esto me lleva a plantear la necesidad de establecer una tipología de las posibles acciones que pueden llevar a cabo los integrantes de la Institución Escolar, considerándola como artificio metodológico que nos permita comprender el modelo de racionalidad que predomina en las diversas situaciones escolares.

\section{UNA TIPOLOGÍA DE LAS ACCIONES QUE SE LLEVAN A CABO EN LA INSTITUCIÓN ESCOLAR}

Como he señalado inicialmente, Habermas propone un esquema analítico, a partir de la teoría sociológica de la acción, donde combina categorías sistémicas con la categoría fenomenológica de «mundo de la vida», tomando como núcleo central de su elaboración teórica el concepto de acción comunicativa. Se sirve del concepto de acción de Weber para delimitar los aspectos empíricos de esta acción orientada al entendimiento, desde la perspectiva de la teoría de la comunicación. La tipología de la acción ofrecida por Habermas, una vez adaptada a las características específicas del ámbito escolar, permitirá comprender desde el punto de vista analítico el nivel de racionalidad que una organización escolar alcanza en sus dinámicas cotidianas, desde la perspectiva de la Teoría Crítica de la Educación.

Tomaré como punto de partida un criterio general que posibilitará la valoración del nivel de calidad educativa alcanzado por una organización escolar, así como del grado de racionalidad $-\mathrm{y}$ por tanto de salud - en que se desarrollan sus funciones:

10. Utilizo el término salud en sentido metafórico para reflejar el concepto de «desarrollo social equilibrado». 
- si la mayoría de las acciones que llevan a cabo los actores implicados en un centro escolar posee carácter comunicativo, fáctica o potencialmente, entonces se podrá afirmar que el nivel de racionalidad alcanzado por esta organización es elevado y, en consecuencia, la calidad educativa del centro también lo será.

Esta argumentación se apoya en varios supuestos previos: el tipo de acciones que caracterizan a la Institución Escolar son las acciones educativas, es decir, aquellas que están encaminadas a la «formación» (Bildung) individual y social de las nuevas generaciones. Desde la perspectiva de la Teoría Crítica de la Educación el referente de tales acciones educativas es la acción comunicativa, pues incluso la función transmisora de conocimientos de esta Institución se asienta sobre una base comunicativa. Pero las acciones educativas no pueden considerarse como propiamente comunicativas, ya que las condiciones de las que se parte en la interacción profesor-alumno nunca pueden ser simétricas a causa de la diferente situación evolutiva de éstos -si lo fueran la acción educativa dejaría de tener sentido en cuanto tal ${ }^{\mathrm{B}}$. Pero si no pueden ser comunicativas de facto, sí que pueden serlo potencialmente, es decir, pueden estar orientadas al logro de futuras acciones comunicativas - mediante el desarrollo de competencias comunicativas, que podrán ser realizadas en la futura fase de adulto del alumno cuando se cumplan las condiciones de simetría precisas.

Debo añadir a esto que, si bien las acciones específicas de la Institución Escolar son de naturaleza educativa, esta Institución como tal es una organización humana con unos fïnes sociales específicos. Los miembros de esta organización social -desde el punto de vista de la teoría de la acción y el interaccionismo simbólico-, actúan de formas diversas en función de expectativas intersubjetivas o de intencionalidades subjetivas. Esto me lleva a introducir en este esquema analítico, otro tipo de acciones que permitan dar razón de las dinámicas que se producen en el seno de los centros escolares (en fig. 6).

11. «Formación» entendida en la perspectiva humanística alemana.

12. He de puntualizar que no identifico las acciones transmisoras del conocimiento con acciones comunicativas, ya que la diferencia entre ambas es evidente, pero sí considero que para que la instrucción -como mera transmisión de saberes- se produzca, es preciso que exista una base de interacción lingüística cuya concreción fáctica sean las acciones comunicativas. Si no existen consensos respecto a la coordinación de las acciones a seguir o sobre el sentido de las mismas, difícilmente se puede producir esta transmisión de conocimientos.

13. El hecho de considerar una situación asimétrica entre adulto y niño (profesor y alumno) no significa que se objetualice la relación del primero respecto al segundo. Cuando un profesor se propone una acción educativa busca el desarrollo de competencias comunicativas en el alumno, cualquiera que sea el estadio evolutivo en que éste se encuentre. Para lograr este desarrollo es imprescindible que el profesor proporcione, en primer lugar, recursos comunicativos y argumentativos al escolar; en segundo lugar, un espacio de libertad donde éste pueda ejercer su incipiente capacidad decisoria y crítica

14. Me estoy refiriendo a una situación-tipo, que no describe la pluralidad de situaciones reales. Con esto quiero decir que la simetría en cuanto a condiciones de los participantes en acciones comunicativas es una condición metodológica que no fáctica en todos los casos. Ciertamente la realidad confirma que existen muchas relaciones entre adultos que a pesar de estar en períodos evolutivos similares no responden a estas condiciones simétricas debido a las diferentes capacidades o grado de competencia comunicativo de cada uno. Este planteamiento es un constructo y por tanto se presupone que cualquier participante adulto capaz de lenguaje y acción se encuentra en condiciones de poder establecer una interrelación simétrica. Otra cosa son las asimetrías por el ejercicio arbitrario del poder. 
Con estos presupuestos iniciales, se propone aquí una tipología de las acciones que se llevan a cabo en la Institución Escolar por los actores integrantes de cada una de las organizaciones escolares concretas. La perspectiva teórica desde la que planteo este referente analítico es la teoría sociológica de la acción, tal como la propone Habermas, con un enfoque simbólico y comunicativo donde el concepto de acción comunicativa no sólo servirá como criterio para el análisis sino también para reorientar la acción educativa en esa misma dirección.

El punto de partida es el concepto de acción de Weber:

«Por "acción" debe entenderse una conducta humana (bien consista en un hacer interno o externo, ya en un omitir o permitir) siempre que el sujeto o los sujetos de la acción enlacen a ella un sentido subjetivo» (Weber, 1944, p. 5).

Pero la definición de Weber presenta un claro reduccionismo al centrarse en la actividad teleológica de un individuo solitario y, aunque incluye el aspecto del «sentido», olvida el carácter intersubjetivo y comunicativo de la acción. Este carácter procede de las reglas y normas a las que responden las acciones y que vienen intersubjetivamente reconocidas (Habermas, 1989, p. 21). Tales normas diferencian un acto intencional, humano, de un simple comportamiento que sólo es fruto de una respuesta a estímulos. La limitación que ofrecen las tesis de Weber es que al considerar el concepto de acción teológica, como categoría central de su teoría de la acción, no deja espacio para el concepto de interacción creadora de sentido, de intersubjetividad. Por ello, la clasificación que hace de los diferentes tipos de acción se basa en los diversos tipos de fines por los que el actor orienta su actividad teológica: fines utilitarios, valorativos y afectivos. Así su «tipología oficial de la acción» contempla estos cuatro tipos: «racional con arreglo a fines, racional con arreglo a valores, afectiva y tradicional» (Weber, 1944, p. 20). Pero, al considerar la acción teleológica como exponente máximo de racionalidad, su tipología de la acción queda jerarquizada según un orden decreciente de racionalidad, siendo la primera de ellas (la acción racional con arreglo a fines) la que presenta un grado de racionalidad (instrumental) más elevado.

Como esta taxonomía no le permite dar razón de las consecuencias sociales de la acción, Weber desarrolla otras nuevas categorías que podrían constituir una tipología «no oficial» partiendo del concepto básico de acción social. Y en esta elaboración se encuentra con que a los mecanismos de coordinación de dicha acción les subyace otro modelo de racionalidad. Esta acción social varía, según si dichos mecanismos de coordinación responden a tramas de intereses o bien a consensos normativos. De esta forma distingue entre la existencia de un orden económico que sólo responde a intereses negociados, y un orden jurídico que se basa en el reconocimiento de pretensiones normativas de validez ${ }^{15}$. El punto débil de esta nueva tipología, es que no acaba de desarrollar un

15. Esta tipología no oficial es presentada por Habermas, de la siguiente manera (En Habermas, 1989 , p. 383);

1. Acciones coordinadas mediante tramas de intereses: 1.1 acciones basadas en una habituación mecánica (costumbre), cuyo grado de racionalidad sería bajo; 1.2. acciones estratégicas (gobernadas por intereses) cuyo grado de racionalidad sería alto

2. Acciones coordinadas mediante acuerdo normativo: 2.1. acciones consensuales basadas en la convención (acción comunitario), cuyo grado de racionalidad sería bajo; 2.2. acciones con- 
modelo de racionalidad con arreglo a valores que dé una explicación consistente de estas acciones, ya que Weber sigue optando por el modelo racional de la «acción racional con arreglo a fines».

Habermas se apoya inicialmente en esta tipología de la acción social weberiana (no oficial), al elaborar su propio modelo (fig. 4), introduciendo la categoría de acción comunicativa para dar razón de aquellas acciones sociales que responden a los acuerdos normativos y que él considera orientadas al entendimiento:

\begin{tabular}{|l|l|l|}
\hline $\begin{array}{l}\text { Orientaciones } \\
\text { de la la acción } \\
\text { de lán }\end{array}$ & Acción orientada al éxito & $\begin{array}{l}\text { Acción orientada al enten- } \\
\text { dimiento }\end{array}$ \\
\hline No-social & Acción Instrumental & \\
\hline Social & Acción estratégica & Acción Comunicativa \\
\hline
\end{tabular}

Figura 4. Tipos de acción (Habermas, 1987a col 1, p. 366).

Habermas aclara este esquema de la siguiente forma:

El modelo de acción racional con arreglo a fines (racionalidad instrumental) considera que el actor se orienta hacia la consecución de metas bien precisadas en cuanto a fines concretos. Para ello elige unos medios adecuados a la obtención de estos fines y considera las otras consecuencias previsibles de la acción como condiciones colaterales del éxito. El éxito queda definido por el logro de los fines deseados y puede ser alcanzado de forma causal mediante acciones u omisiones previamente calculadas. Bajo este modelo de racionalidad se encuentran la acción instrumental y la acción estratégica, ambas orientadas al éxito, si bien difieren en la naturaleza no social o social de una y otra. Estas quedan definidas de la siguiente forma:

- Una acción orientada al éxito es instrumental «cuando la consideramos bajo el aspecto de observancia de reglas de acción técnicas y evaluamos el grado de eficacia de la intervención que esa acción representa en un contexto de estados y sucesos» (Habermas, 1987a, vol. 1. p. 367).

- Una acción orientada al éxito es estratégica «cuando la consideramos bajo el aspecto de observancia de reglas de elección racional y evaluamos su grado de influencia sobre las decisiones de un oponente racional» (Habermas, 1987a, vol 1. p. 367).

- Una acción es comunicativa «cuando los planes de acción de los actores implicados no se coordinan a través de un cálculo egocéntrico de resultados, sino mediante actos de entendimiento. En la acción comunicativa los participantes no se orientan primariamente al propio éxito: antes persiguen sus fines individuales bajo la condición de que sus respectivos planes de acción puedan armonizarse entre sí sobre la base de una definición compartida de la situación» (Habermas, 1987a, vol 1. p. 367).

sensuales de tipo postconvencial (acción societaria), cuyo grado de racionalidad sería alto (Véase Weber, 1944, pp. 18-25). 
Pero Habermas considera de mayor interés para una teoría sociológica centrarse en aquellas acciones que puedan dar razón de cómo se constituye el orden social. Por este motivo dirige su atención sobre las acciones sociales de esta tipología (acción estratégica y acción comunicativa), ya que éstas permiten explicar cómo los sujetos coordinan sus acciones sobre los que se construyen los entramados sociales. Con estos planteamientos Habermas presenta la siguiente clasificación:

\begin{tabular}{|l|l|l|l|l|}
\hline $\begin{array}{l}\text { Características. } \\
\text { Tipos de Ac- } \\
\text { ción }\end{array}$ & $\begin{array}{l}\text { Orientación de } \\
\text { la acción }\end{array}$ & $\begin{array}{l}\text { Actitudes bá- } \\
\text { sicas }\end{array}$ & $\begin{array}{l}\text { Pretensiones } \\
\text { de validez }\end{array}$ & $\begin{array}{l}\text { Referencia al } \\
\text { mundo }\end{array}$ \\
\hline $\begin{array}{l}\text { Acción estraté- } \\
\text { gica }\end{array}$ & $\begin{array}{l}\text { Orientada al } \\
\text { éxito }\end{array}$ & Objetivante & Eficacia & Mundo objetivo \\
\hline $\begin{array}{l}\text { Acto de habla } \\
\text { constatativo }\end{array}$ & $\begin{array}{l}\text { Orientada al } \\
\text { entendimiento }\end{array}$ & Objetivante & Verdad & Mundo objetivo \\
\hline $\begin{array}{l}\text { Acción regula- } \\
\text { da por normas }\end{array}$ & $\begin{array}{l}\text { Orientada al } \\
\text { entendimiento }\end{array}$ & $\begin{array}{l}\text { De conformi- } \\
\text { dad con las } \\
\text { normas }\end{array}$ & Rectitud & Mundo social \\
\hline $\begin{array}{l}\text { Autopresenta- } \\
\text { ción expresiva }\end{array}$ & $\begin{array}{l}\text { Orientada al } \\
\text { entendimiento }\end{array}$ & Expresiva & Veracidad & Mundo interno \\
\hline
\end{tabular}

Figura 5. Casos puros de acción (Habermas, 1989, p. 388).

Por acción estratégica entiende Habermas aquellas acciones que son siempre sociales y que conllevan la observancia de reglas de elección racional, siendo evaluadas como eficaces cuando se ha logrado influir sobre las decisiones de otro sujeto (Habermas, 1989 , p. 385). A estas acciones opone las acciones comunicativas en las que los actores participantes se orientan no hacia el propio éxito ${ }^{6}$ sino hacia el mutuo entendimiento. Estas acciones comunicativas pueden analizarse y presentarse según los criterios derivados de su estructura de racionalidad, es decir, según las pretensiones de validez que contiene un acto de habla. Así un acto de habla puede cuestionarse o aceptarse desde tres aspectos diferentes: bajo el aspecto de verdad, el de rectitud normativa o el de veracidad (sinceridad).

El modo de expresión ilocucionaria señala a qué tipo de pretensión estamos recurriendo por lo que, para el análisis, los actos comunicativos quedan desglosados en:

- actos de habla constatativos, en los que se emplean oraciones enunciativas elementales. La pretensión de validez a la que apelan es la de verdad. La actitud que adop-

16. El término «éxito» aquí empleado es entendido como resultado, como logro del fin propuesto. Este término lo aplica Weber a la acción racional con arreglo a fines cuyo resultado es un cambio en un estado de cosas en el mundo. Por eso las acciones estratégicas, que constituyen uno de los tipos de acción racional con arreglo a fines, están orientadas hacia este resultado mientras que las comunicativas, que están orientadas al entendimiento, se centran en este proceso de entendimiento. 
tan los participantes en la interacción comunicativa es objetivante y se refieren a algo que sucede en el mundo objetivo.

- actos de habla institucionalmente ligados, que sólo pueden ponerse en correspondencia con contextos normativos determinados (el matrimonio, una apuesta, el bautismo, etc). La pretensión de validez a la que apelan es la rectitud. La actitud de los participantes es de conformidad con las normas y el mundo al que se refieren es el social.

- actos de habla expresivos, en los que se utilizan oraciones elementales de vivencia, hablándose en primera persona del presente de indicativo. La pretensión de validez es la veracidad entendida como sinceridad. La actitud de los participantes es expresiva y el mundo al que se refieren es el interno, el subjetivo.

Esta tipología de la acción presentada por Habermas puede facilitar una aproximación comprensiva a las dinámicas cotidianas que se originan en el seno de la Institución Escolar, permitiendo valorar el grado de calidad educativa de la organización así como el tipo de racionalidad en el que se mueven los miembros de esta Institución en situaciones específicas, para someterlas a crítica y poder corregirlas. El criterio de evaluación empleado será el ya señalado inicialmente: la aproximación de las acciones escolares al modelo de acción comunicativa.

Pero para adaptar la tipología de la acción habermasiana a la Institución Escolar es necesario introducir algunas modificaciones que permitan dar razón de la especificidad de las acciones dentro de esta Institución.

Previamente a ello, hay que señalar una serie de características que son inherentes a las acciones que se realizan en su seno, y que deberán tenerse en cuenta a la hora de realizar una clasificación de las acciones en el ámbito escolar:

1. Todas las acciones que realizan los actores miembros de una comunidad escolar son de carácter social. Incluso las referidas al propio mantenimiento estructural de la institución, como puedan ser el cumplimiento de las gestiones burocráticas en un centro o la planificación del mapa escolar de la provincia, tienen naturaleza social aunque la interacción no se produzca en un «cara a cara», ya que la intención que rige tales acciones tiene en cuenta las necesidades de otros. Esto es así porque la Institución Escolar tiene, como tal institución, una naturaleza social.

2. Todas las acciones escolares, como señala Habermas respecto a las acciones sociales, tienen una estructura teleológica (Habermas, 1987a, vol. 1, p. 146), es decir, todas persiguen un fin. La diferencia entre ellas estriba en cuál sea la orientación de esta finalidad. Una veces ésta pueda tener carácter instrumental, como en las acciones anteriormente citadas de la gestión burocrática escolar, y otros irán encaminadas hacia el entendimiento interpersonal. En el primer caso diremos que tales acciones están orienta-

17. Esta indicación gramatical es referencial, no se alude aquí al uso de metáforas expresivas.

18. Me apoyo aquí en la concepción Weber sobre la acción social: «La acción social (incluyendo tolerancia u omisión) se orienta por las acciones de otros, las cuales pueden ser pasadas, presentes o esperadas como futuras. Los «otros» pueden ser individualizados y conocidos o una pluralidad de individuos indeterminados y completamente desconocidos (el «dinero», por ejemplo, significa un bien -de cambio- que el agente admite en el tráfico porque su acción está orientada por la expectativa de que otros muchos, ahora indeterminados y desconocidos, están dispuestos a aceptarlo también, por su parte, en un cambio futuro)» (Weber, 1944, p. 18). 
das al éxito, entendiendo por tal el resultado de la acción como logro de los fines propuestos. En el segundo caso indicaremos que están orientadas al entendimiento, suponiendo con ello que nos centramos en el proceso comunicativo ${ }^{9}$ entendido como fin en sí mismo. Con las primeras se trata del logro de un cambio en un estado de cosas, situación, decisiones de otras personas, acciones de otros, pensamientos, etc.; en las segundas, el fin consiste en establecer un proceso de comunicación racional.

3. Todas las acciones que se llevan a cabo en el seno de la Institución Escolar tienen el soporte de un lenguaje. Esto no quiere decir que por ello sean ya de carácter comunicativo. Habermas no equipara lenguaje con comunicación, diferenciando los actos de comunicación espontáneos de aquellas acciones comunicativas o discursos que pretenden una reflexión intersubjetiva racional y el logro de un acuerdo. Así pues, aunque una acción sea de carácter lingüístico, como un acto de habla, puede tener una orientación estratégica donde el entendimiento sea un vehículo para el éxito de los fines buscados por el agente (la exposición verbal del contenido de un tema que un profesor hace ante sus alumnos puede tener como orientación un fin estratégico, como sería el impresiona a éstos o mostrar su autoridad) y, por tanto, no puede ser considerada como una acción comunicativa. Para que la acción sea comunicativa ha de cumplir una serie de condiciones, ya expuestas anteriormente, y su finalidad ha de referirse a la concreción de la racionalidad comunicativa a una acción cuando ésta se oriente hacia el entendimiento. Para el análisis de estas acciones se contará con la ayuda de la pragmática universal, valiéndose de un enfoque metodológico integrado por tres perspectivas distintas: hermenéutica, empírica y crítica-ideológica?

4. Así pues, para considerar de un tipo u otro una acción en el ámbito escolar, deberemos tener presente:

- la intencionalidad del agente;

- la percepción de esta intencionalidad por parte de los participantes en la interacción;

- los efectos o consecuencias de la acción tanto para el propio agente como para los implicados en la interacción.

5. Conviene subrayar que no todas las acciones que se realizan en el ámbito escolar son educativas en sí mismas, aunque sirvan de soporte para que éstas puedan llevarse a cabo. Este es el caso de aquellas acciones encaminadas a la integración sistémica de la organización o las que se llevan a cabo en las interacciones entre miembros adultos de la comunidad escolar cuya intencionalidad no es educativa.

19. En las acciones comunicativas el logro, o éxito, viene determinado por la obtención del acuerdo que permite coordinar intersubjetivamente las acciones posteriores.

20. Entiendo por lenguaje cualquier medio de comunicación intersubjetiva, como el lenguaje verbal (oral y escrito), el lenguaje de los gestos, el lenguaje plástico, el lenguaje musical... Como señala Benjamín: «Toda expresión de la vida espiritual de un hombre puede concebirse como una especie de lenguaje (...). En una palabra, cada comunicación de contenidos espirituales es lenguaje, y la comunicación por medio de la palabra es sólo un caso particular del lenguaje, y la comunicación por medio de la palabra es sólo un caso particular del lenguaje humano». Benjamín, W. (1991), «Sobre el lenguaje en general y sobre el lenguaje de los humanos» en Para una crítica de la violencia y otros ensayos, Madrid, Taurus, p. 59.

21. La exposición de este planteamiento metodológico integrado puede verse en Gimeno Lorente, P. (1993). 
Considero como acciones educativas aquellas acciones intencionales cuya finalidad -inmediata o futura- es la formación (Bildung) del alumno según los criterios de una teoría educativa crítica y cuyos agentes son los adultos profesionales, integrantes de la comunidad escolar. Estas acciones educativas se producen en condiciones asimétricas de los participantes en la interacción, es decir, existe una desigualdad evolutiva del adulto o agente educativo respecto al alumno, niño o joven en proceso de maduración (cognitiva, emotiva, interactiva y comunicativa) o sujeto a quien se desea formar. Una interacción entre adultos (por definición, simétrica) no tiene carácter educativo a causa de la naturaleza formativa de la educación. Como el referente de las acciones educativas es la acción comunicativa y éste, por la asimetría citada de los participantes en la interacción, no es posible, considero que tales acciones educativas habrán de ser «potencialmente comunicativas», es decir, habrán de estar intencionalmente encaminadas al desarrollo de las competencias comunicativas en el niño o adolescente que le permitan llevar a cabo, en su vida de adulto, acciones comunicativas. Las acciones educativas deberán ser progresivamente comunicativas en función del grado creciente de desarrollo madurativo del alumno. Esta situación puede representarse gráficamente del siguiente modo:

Acción educativa $\rightarrow \rightarrow \rightarrow$ Acción comunicativa,

En esta evolución las acciones educativas deben utilizar los mecanismos de mediación necesarios para ir paulatinamente desapareciendo como tales, dejando espacio para futuras acciones plenamente comunicativas.

Así pues la tipología de las acciones que establezco como referente analítico de la vida social en una organización escolar es la siguiente:

\begin{tabular}{|c|c|c|}
\hline \multirow{2}{*}{$\begin{array}{l}\text { Acción orientada } \\
\text { al producto (éxito) }\end{array}$} & Acción instrumental & \\
\hline & Acción estratégica & \\
\hline \multirow{2}{*}{$\begin{array}{c}\text { Acción orientada al } \\
\text { proceso (entendimiento) }\end{array}$} & Acción Comunicativa & $\begin{array}{l}\text { Acto de habla constatativo } \\
\text { Acción regulada por normas } \\
\text { Acción autoexpresiva }\end{array}$ \\
\hline & $\begin{array}{l}\text { Acción potencialmente } \\
\text { Comunicativa } \\
(\text { Educativa })\end{array}$ & $\begin{array}{l}\text { Acto de habla constatativo } \\
\text { Acción regulada por normas } \\
\text { Acción autoexpresiva }\end{array}$ \\
\hline
\end{tabular}

Figura 6. Tipología de las acciones escolares

22. No se consideran aquí a los padres de los alumnos, ya que si bien tienen intenciones educativas, se diferencian de los profesionales de la educación (profesores, pedagogos, psicólogos, trabajadores sociales educativos) en que no actúan con una planificación sistemática de tales intenciones. En este artículo me refiero concretamente al ámbito educativo institucional, y a los niveles de Infantil, Primaria y Secundaria, que es donde se puede hablar de educación. 


\section{Acciones orientadas al producto ${ }^{3}$}

1.1. Acciones instrumentales: Están orientadas al logro de un cambio (éxito) en un estado de situaciones propias del mundo social. Su finalidad estriba en el mantenimiento del equilibrio sistémico de la Institución Escolar, en general, o de las organizaciones escolares específicas, en particular. Ejemplo de éstas las hallamos en las acciones relativas a la gestión burocrática del centro, como el cumplimiento de los Documentos Oficiales del Centro (D.O.C.), cuyo fin es mantener la estructura institucional de la propia organización. Unidas a éstas, que presentan un carácter formal, existen otro tipo de acciones de carácter simbólico, orientadas al logro del mismo fin. Me refiero a todas aquellas acciones de naturaleza simbólica (significados, contenidos culturales, valores, normal, actitudes...) -como la transmisión de un concepto de disciplina-, que contribuyen al mantenimiento de la Institución Escolar como tal institución y que se hallan enraizadas en los procesos de reproducción estructural de la sociedad (fines explícitos, o no explícitos, del currículo encaminados a la reproducción cultural y social).

Otro tipo de acciones instrumentales, muy frecuente en los centros escolares, son las acciones de enseñanza encaminadas al logro de un aprendizaje procedimental o «instrumental» (lecto-escritura, reglas ortográficas, un hábito de comportamiento,...). En éstas el profesor se plantea un determinado objetivo respecto a los alumnos cuando pretende que éstos adquieran una determinada destreza, habilidad o conocimiento, e intenta poner los medios más adecuados para la obtención de ese resultado que se persigue. Es la acción instructiva por excelencia.

1.2. Acciones estratégicas: tienen en común con las anteriores que también están orientadas al producto, pero en este caso el resultado se produce en la propia interacción. En dicha interacción el agente instrumentaliza al otro participante en la interacción convirtiéndolo en medio para la obtención del fin que persigue. Esta instrumentalización consiste en influir sobre las decisiones o comportamientos del otro, de forma que contribuya sin saberlo a los fines que pretende el primero. Ejemplo de éstas lo encontramos en interacciones como las que se producen en el transcurso de un claustro de profesores, cuando un miembro del mismo persigue un fin que no explicita ante los compañeros y, mediante coacciones veladas o estrategias predeterminadas, pretende influir sobre las decisiones de los otros para conseguir sus propios fines. El éxito de estas acciones reside en el logro de la influencia velada sobre los otros. En las dinámicas escolares son frecuentes estas acciones estratégicas en las relaciones entre profesores o entre profesores y padres, aunque también se producen entre los alumnos, cuando se instrumentalizan en-

23. «Producto» entendido como sinónimo del término habermasiano de «éxito», es decir, del logro del fin como cambio en un estado de cosas pertenecientes al mundo social o al subjetivo. Esta es la diferencia que establezco respecto al modelo weberiano de acción orientada al éxito. Estas se orientan al resultado de un cambio de estado de cosas en el mundo objetivo. En este modelo estos resultados, están referidos a cambios en el mundo social o personal, a causa de la naturaleza social de la Institución Social.

24. Los fines, en estas acciones estratégicas, no se refieren tanto al logro de determinados efectos como al logro de una influencia sobre los demás. Por otra parte cuando una acción se denomina estratégica es porque en ella se instrumentaliza al otro en función de «mis propios fines», es decir, de aquellos fines que están orientados a la obtención de un beneficio para el agente. 
tre sí para la obtención de un fin (el alumno que se aprovecha del trabajo en equipo para eludir su responsabilidad personal en el aprendizaje..., por ejemplo).

\section{Acciones orientadas al proceso (entendimiento)}

2.1. Acciones comunicativas: se hallan orientadas al entendimiento racional. Este es el caso de aquellas interacciones que, con el fin de lograr un acuerdo racionalmente motivado, se producen entre los adultos de la comunidad escolar. En éstas no caben estrategias ni fines orientados al beneficio individual. Lo que se pretende es la coordinación de las acciones de los participantes en ellas. Son la base racional de la vida escolar y el referente al que están orientadas todas las acciones de carácter educativo (formativo). Como resultado paradigmático de acciones comunicativas puede citarse un Proyecto Edueativo y Curricular elaborado a partir de consensos racionalmente motivados, donde los participantes hubieran interactuado en condiciones simétricas y libres de coacciones.

Estas acciones comunicativas pueden desglosarse según el aspecto por el que se les puede cuestionar (según la pretensión de validez racional a la que respondan), entendiéndose por acción la propia emisión comunicativa:

2.1.1. Actos de habla constatativos: cuando en las emisiones comunicativas se emplean oraciones enunciativas elementales (con efecto ilocucionario) haciéndose referencia a hechos objetivos. Suelen darse en interacciones entre profesores donde se tratan temas de carácter profesional, por ejemplo, cuando se toman decisiones relativas a principios teóricos -psicológicos o pedagógicos- del aprendizaje en la elaboración del Proyecto Curricular de Centro.

2.1.2. Acciones reguladas por normas: cuando las emisiones hacen referencia a contextos normativos. Manifestación de éstas son las decisiones tomadas entre los adul$\operatorname{tos}^{\Im}$ de la Comunidad Educativa cuando elaboran el Reglamento Interno del Centro, o cuando se determinan una serie de normas de convivencia (formal o informal) para el Centro.

2.1.3. Acciones autoexpresivas: cuando en las emisiones se utilizan oraciones elementales de vivencias o valores. Podemos hallar una manifestación de éstas en el debate (mediante acciones comunicativas) que se establezca entre padres y profesores para definir el Proyecto Educativo del Centro. Este tipo de emisión puede darse también en reuniones de profesores cuando se intercambian opiniones o sentimientos sobre las experiencias y vivencias del aula.

2.2. Acciones potencialmente comunicativas: son aquellas definidas como educativas y que han quedado descritas anteriormente. Como muestra de éstas podrían citarse las asambleas que un profesor lleva a cabo con el grupo-clase para elaborar las normas de convivencia del grupo. Según el nivel madurativo de los alumnos, el grado de autonomía de éstos en sus decisiones, así como su capacidad argumentativa, racional, será mayor o menor. Lo mismo sucede con el grado de dirección que debe adoptar el profe-

25. Me refiero a los adultos (profesores, padres) porque aunque los alumnos también tengan participación en ellas, su situación respecto a la comunicación no es simétrica en relación con los otros participantes y, por tanto, su nivel decisorio y de responsabilidad no puede ser el mismo. 
sor. A mayor edad de los alumnos el espacio de libertad decisoria será mayor, en función de la superior capacidad de autonomía de aquéllos.

Este tipo de acciones también cabe ser desglosado según la pretensión de validez racional a la que responda en:

2.2.1. Actos de habla constatativos: cuando las oraciones empleadas son enunciativas y van referidas a un enunciado o descripción del mundo objetivo. Este tipo de emisiones son frecuentes en la transmisión de un contenido de conocimiento referido a un concepto, ley, principio, etc. Se diferencian de las acciones instrumentales en que aquí la finalidad de la acción tiene una clara orientación comunicativa, es decir, lo que le interesa al profesor es que el alumno reflexione críticamente acerca de la información que le ofrece y que entre en debate crítico con él y con sus compañeros (refutando lo dicho con otro principio teórico, o aceptándolo con una afirmación racional del mismo nivel, referida al mundo objetivo, no con una creencia). Se puede apreciar esta diferencia a través del análisis de la metodología utilizada por el profesor o bien de su propia declaración de intenciones compartida por el alumno. Es decir, aquí interesa sobre todo la comunicación, no como medio (como en el caso de la acción instrumental) sino como fin.

2.2.2. Acciones reguladas por normas: en este caso se contemplan aquellas acciones potencialmente comunicativas en las que el profesor busca, en interacción con el alumno, el establecimiento consensuado de normas de convivencia para el aula, o formas de resolución de conflictos, etc. También cabe en ellas el análisis crítico, con fines educativos, de situaciones normativas sociales.

2.2.3. Acciones autoexpresivas: este tipo de acciones se refiere a emisiones en las que el profesor expresa modelos vivenciales de valores, opiniones, etc. y las presenta a los alumnos para que éstos puedan tomar postura crítica frente a ellas. No caben aquí las actitudes dogmáticas del profesor, porque supondría una renuncia al carácter potencialmente comunicativo de la acción y por consiguiente dejaría de ser educativa. También entran en ellas las emisiones referidas a análisis críticos de valores sociales en las que los alumnos participan con su propia aportación, haciendo uso al tematizarlas de argumentos referidos a su propio mundo subjetivo (opiniones, creencias argumentadas...).

Estas acciones, por su naturaleza social, se llevan a cabo sobre contextos interaccionales. Pero antes de pasar a describir estos contextos y su conexión con diversos tipos de racionalidad, considero necesario precisar lo siguiente:

1. Al igual que sucede en otras situaciones sociales no existen acciones que puedan ser clasificadas de un tipo u otro en un sentido «puro». Todas las acciones están teñidas de intereses diversos que les aportan matices estratégicos, instrumentales o comunicativos. Esta clasificación sólo se considera como artificio metodológico que pueda favorecer la comprensión de algunas dinámicas escolares y contribuir a desvelar conflictos

26. Cuando hablo de mundo objetivo, no sólo incluyo el mundo físico, sino también el social si éste es analizado desde una actitud objetivamente.

27. Este tipo de acciones cuyo fin es el logro del entendimiento haciendo uso de oraciones enunciativas descriptivas del mundo objetivo, propio del discurso teórico, es más propio de los últimos niveles de Secundaria. El discurso entre profesor y alumno argumentando sobre la pretensión de verdad de un enunciado, precisa de un nivel evolutivo y de conocimientos que en la mayoría de los temas no poseen todavía los alumnos de etapas anteriores ni, con frecuencia, los de primer ciclo de Secundaria obligatoria. 
latentes o no resueltos. Cuando se considere una acción susceptible de ser clasificada en una categoría u otra, habrá que atenerse al interés predominante, es decir, a la intencionalidad y al sentido que se le da por parte del agente y de los implicados en la interacción.

2. Por otra parte las acciones escolares se producen en forma de secuencia, quedando enlazadas unas con otras. En ocasiones será la propia cadena de acciones completa la que permitirá la comprensión del sentido e intencionalidad de algunos fragmentos de acción aislados.

3. Respecto al contexto en que se llevan a cabo las acciones de una escuela, ya se ha comentado la naturaleza social de ellas, por lo que se puede hablar propiamente de que estas acciones se desarrollan sobre un contexto interaccional. Pero existen también en la vida escolar un tipo de acciones, de carácter instrumental, que se llevan a cabo sobre la relación institucional que se establece entre la propia organización y los subsistemas político, económico y cultural, donde la interacción queda diluida en el anonimato. En este caso hablaré de relaciones funcionales.

4. Esta tipología es aplicable con propiedad en los niveles de la Institución Escolar donde todavía se puede hablar de acciones educativas, es decir, en los niveles de Infantil, Primaria y Secundaria. El nivel de enseñanza superior se desarrolla en organizaciones (Universidad, Centros de Enseñanza Superior) que tienen un carácter instructivo, pero no educativo, ya que el nivel evolutivo de los estudiantes coloca a éstos en posición de autonomía respecto a su propia formación (al menos como principio).

Una vez hechas estas aclaraciones puede considerarse que las acciones que se llevan a cabo en un centro escolar se desarrollan sobre los siguientes contextos.

1. Relaciones funcionales entre la organización escolar concreta y los subsistemas de quienes depende (político, económico y socio-cultural).

2. Interacciones entre los miembros adultos de una organización escolar (profesores, profesionales de la educación con incidencia en el centro, padres).

3. Interacciones entre adultos y adolescentes-niños (alumnos).

4. Interacciones entre alumnos.

Sobre cada uno de estos contextos se pueden llevar a cabo las siguientes acciones:

En 1. Relaciones funcionales: sobre este contexto el tipo de acciones predominante tiene un carácter instrumental. Se trata de aquellas acciones que tienen un carácter burocrático y que permiten la gestión institucional del centro, o las de planificación económica realizadas por la Administración. Este tipo de acciones tienen como finalidad la propia pervivencia de la organización y por tanto cumplen la función de integración sistémica de la Institución en general. Habitualmente éstas vienen desarrolladas en los Centros por el Secretario o el Director, y en la Administración educativa por gestores (Jefes de Planificación de las diferentes Direcciones Generales). Presentan un cierto parecido con las que puede llevar a cabo una organización empresarial pero son muy diferentes en su esencia, ya que no podemos olvidar que los fines de una escuela no son de naturaleza económica o productiva sino simbólica. Por ello, en la propuesta teórico-crítica de Institución Escolar que aquí se señala, estas acciones deberían responder a una racionalidad comunicativa, supeditando los criterios instrumentales a los morales ${ }^{8}$ a través de procesos

28. Parto del presupuesto teórico de que el concepto de acción racional con arreglo a fines, cuyo principal exponente es el trabajo, está estrechamente ligado al concepto de interacción sim- 
comunicativos con los implicados en ellas. Acciones de este tipo son las decisiones político-administrativas sobre las plantillas de profesores en los centros. Tales decisiones frecuentemente responden a criterios de racionalidad instrumental ya que se encuentran respaldadas por argumentos económicos. Una Institución Escolar que obedeciera a un modelo crítico debería, en estas decisiones, analizar las características particulares de cada centro para determinar en función de las necesidades concretas y específicas, no contempladas por la norma general, el número de profesores, tomándose esta decisión a través de procesos comunicativos con los implicados y tomando como referencia criterios práctico-morales y no prioritariamente instrumentales.

En 2. Interacciones entre adultos: las acciones posibles sobre la interacción entre adultos miembros de una comunidad escolar pueden tener un carácter estratégico o comunicativo. Ejemplo del primer tipo son aquéllas que realiza un Director, Jefe de Estudios, Coordinador de Departamento, etc., cuando intenta influir sobre otro profesor sirviéndose de su rol, para que éste adecúe su comportamiento o actitudes a sus expectativas o intereses. El agente pretende el logro de sus propios fines, no el entendimiento entre ambos ${ }^{9}$ participantes en la interacción. Pero la capacitación -al menos por principio-, de los adultos de un centro escolar, para poder llevar a cabo acciones comunicativas, permite esperar que se puedan producir entre ellos acciones de esta naturaleza. Ejemplo de acción comunicativa sería el establecimiento de acuerdos sobre alguno de los componentes del currículo en una reunión de Ciclo o Departamento. Para que se pueda hablar con propiedad de un acuerdo basado en una acción comunicativa, es necesario que no haya existido ningún tipo de coacción en el proceso comunicativo, así como que las decisiones adoptadas estén apoyadas sobre argumentos racionales que cumplan las tres pretensiones de validez del discurso en lugar de, únicamente, sobre votaciones donde lo que prima es el número de votos. La manifestación de estos tipos de acciones se pueden extender a las relaciones entre profesores y padres. El establecimiento de un marco axiológico educativo, que tiene su plasmación en el Proyecto Educativo de Centro, debería realizarse mediante acciones comunicativas libres de dominio, donde se obtengan consensos auténticos.

En 3. Interacciones adultos-alumnos: sobre las interacciones que se establecen entre los adultos -generalmente los profesores- de la comunidad escolar y los alumnos, se pueden dar acciones instrumentales, estratégicas y potencialmente comunicativas. Ejemplo de las primeras son las acciones de planificación y desarrollo del currículo. El profesor se propone una serie de fines de carácter instructivo y formativo y diseña los medios

bólicamente mediada. Por ello aunque hable de acciones de naturaleza instrumental, en éstas siempre surgirán aspectos relativos al mundo de la vida práctico-moral, ya que la sociedad se reproduce sobre esta doble vía (reproducción material-reproducción simbólica) pero totalmente integrada una en otra. En este sentido comparto la opción evolutiva de Habermas, y de la Escuela de Frankfurt primera, frente a perspectivas más reduccionistas.

29. Utilizo el término «ambos» para señalar paradigmáticamente los dos miembros que son precisos, al menos, en una interacción. No supone esto que tal interacción no pueda ser establecida entre una persona y un grupo, o entre dos o más grupos.

30. La contaminación de los actuales procesos democráticos apoyados en número de votos y no en análisis críticos sobre la racionalidad de las propuestas, influye con frecuencia en los procesos de toma de decisiones de las escuelas. Suele existir una gran resistencia para aceptar que es más importante un buen argumento que no un número determinado de votos o manos alzadas. 
adecuados para el logro de aquéllos. Ahora bien, el desarrollo del currículo precisa de una base comunicativa con los alumnos que permita el logro de los objetivos previstos o su reformulación. Aquí se habla de acciones potencialmente comunicativas cuando el profesor pretende introducir progresivamente al alumno en la toma de decisiones respecto a su propio proceso de aprendizaje. Con esto quiero decir que aunque sea el profesor quien, como profesional que conoce el contenido de la materia o tema a transmitir al alumno, planifique en primer lugar cómo ha de ser este proceso, el alumno, conforme va adquiriendo mayores niveles de autonomía y de competencia racional, puede intervenir paulatinamente en la toma de decisiones sobre aspectos referidos a este proceso de enseñanza-aprendizaje, así como asumir cada vez mayores niveles de responsabilidad en cuanto a la organización y dirección de su aprendizaje. Esta progresiva autonomía se hace evidente en cuestiones práctico-morales, como el establecimiento de normas de convivencia para el grupo-clase, por ejemplo. En esta cuestión la participación del alumno se puede establecer desde el momento en que llega a la escuela, pues hasta los niños de la etapa de Infantil pueden «aprender a decidir» sobre normas referidas a su trato con otros compañeros o sobre sí mismos.

En esta interacción los agentes de las acciones pueden ser, asimismo, los alumnos en su relación con los profesores (o padres). También los escolares tienen la posibilidad de actuar estratégicamente respecto a los profesores, ${ }^{2}$ pero en tales interacciones debería predominar siempre el aspecto educativo por lo que el profesor deberá intentar reconducir tales acciones hacia otras más próximas a las comunicativas.

En 4. Interacciones entre alumnos: En la interacción entre alumnos se pueden llevar a cabo acciones estratégicas, si bien, como en el caso anterior, la finalidad educativa del profesor deberá ser reconducirlas hacia acciones potencialmente comunicativas. Ejemplo de las primeras serían aquellas acciones en las que un alumno coacciona afectiva, moral o físicamente, a otro compañero para que asuma una responsabilidad que le compete al primero, como pueda ser la realización de un trabajo. Pero también los alumnos pueden establecer acciones comunicativas entre sí, a su nivel, intentando llegar a acuerdos mediante el uso de argumentos en lugar de recurrir a medios coactivos como la fuerza verbal o física.

Acerca de las segundas cabe hablar de la necesidad de una capacitación progresiva para ellas en función de su desarrollo madurativo y su adquisición de competencias cognitivas, interactivas, morales y lingüísticas (comunicativas). Es tarea del profesor mostrar al alumno, en primer lugar a través del ejemplo, cómo pueden ser este tipo de acciones comunicativas y en segundo lugar, es necesario que se presente el proceso de entendimiento de forma secuenciada y aplicado a situaciones concretas. Esto incluye, asimismo, establecer un espacio de libertad y posibilidad (como el trabajo en grupo, o la organización del trabajo general por parte de los escolares) para que el alumno pueda hacer sus propios ensayos comunicativos en las interacciones con los compañeros.

31. Estas acciones instrumentales si bien no son críticas en sí mismas, sí pueden serlo potencialmente cuando contribuyen a proporcionar instrumentos cognitivos y procedimentales a los alumnos para acceder a un conocimiento crítico de la realidad. Tales acciones son imprescindibles para poder desarrollar posteriormente el pensamiento crítico del alumno.

32. Este es el caso de las acciones de contestación o huida de los alumnos frente a la escuela. Es necesario tenerlas presentes porque forman también parte del currículo latente en la escuela, y pueden condicionar desde el desarrollo del currículo hasta su orientación. 
Finalmente deseo hacer una breve consideración sobre lo aquí expuesto. Si bien mi intención ha sido la de aportar un marco analítico que permita comprender mejor las acciones que se llevan a cabo dentro de una organización escolar para poder apreciar el tipo de racionalidad predominante en ella, así como orientar la acción educativa, soy consciente de que la realidad escolar no es categorizable únicamente mediante esquemas de acción sociológica, ya que todas ellas están llenas de significados simbólicos (valores, normas, esquemas interpretativos, sentimientos...). Mi pretensión ha sido aprovechar el marco categorial ofrecido por Habermas para, al adoptar una cierta distancia respecto a los fenómenos escolares, poder desvelar el tipo de racionalidad que prima en una situación cotidiana de la escuela, así como clarificar los conflictos que surgen en ella cuando los participantes no tienen presente, la naturaleza mixta, sistémica y simbólica, de la Institución Escolar y poder introducir aquí, procesos de crítica ideológica.

Por ello, partiendo de la tesis de Habermas acerca de los componentes de racionalidad que presentan las acciones (Habermas, 1987a, vol. 1, p. 428) propongo el siguiente cuadro donde se puede apreciar la conexión que tienen los diferentes tipos «puros» de acción que se presentan en las organizaciones escolares con el modelo de racionalidad consiguiente.

El interés de esta asociación entre los diversos tipos que se llevan a cabo en la Institución Escolar y los diferentes modelos de racionalidad reside en que permite comprender dos aspectos constitutivos de la realidad escolar:

a) En primer lugar y desde una perspectiva macrosocial, señala la doble y compleja naturaleza de la Institución Escolar, indicando cómo se conjuga en ella un modelo de racionalidad cognitiva (instrumental) con otro de naturaleza práctica (moral).

b) En segundo lugar y desde una perspectiva microsocial, permite comprender el tipo de racionalidad que impregna las acciones cotidianas de la escuela.

En la figura 7 se presentan enlazadas las acciones orientadas al producto (éxito), es decir, las acciones instrumentales y estratégicas, al considerar que ambas responden al mismo modelo de racionalidad instrumental, ya que ambas se sirven de un saber en forma de técnicas y estrategias, y utilizan como forma de argumentación de sus acciones discursos teóricos.

El significado de discurso se entiende en el sentido empleado por Habermas como aquellos «actos organizados con el fin de razonar emisiones cognitivas», para lo que utilizamos interpretaciones, afirmaciones, explicaciones o justificaciones que aportan una información (Habermas, 1989, p. 102). Estas interpretaciones, afirmaciones, explicaciones o justificaciones, cuando se asocian a enunciados teoréticos, configuran los discursos teóricos demostrando (o intentando comprobar) la validez en cuanto a la verdad

33. Habermas diferencia entre discurso y acción comunicativa como interacción lingüística. En el primer caso se refiere a aquellas acciones comunicativas en las que las pretensiones de validez se convierten en tema, es decir, pueden ser problematizadas explícitamente. En el caso de la acción comunicativa entendida como interacción, las emisiones o manifestaciones se emplean para intercambiar o aportar información (Habermas, 1989, p. 108). A mi juicio, Habermas no es suficientemente riguroso en el uso de estos términos en todos sus textos, ya que en realidad el concepto general de acción comunicativa lo emplea abarcando estas dos formas de comunicación. Mi interpretación en el empleo del concepto acción comunicativa recoge el significado más amplio, si bien el término discurso añade el matiz crítico-racional. 
de los enunciados expuestos. Así, en el caso de una acción instrumental como pudiera ser la enseñanza de la técnica de la lectoescritura, el saber que se utiliza es una técnica de aprendizaje lector (global, sintética, u otra); la manera en que se argumenta este tipo de técnica empleada hace referencia a una teoría del aprendizaje, para lo que se emplea un discurso teórico, y la manifestación de tal acción es el logro de ese aprendizaje por parte del alumno (producto). Tal acción estará regida por una racionalidad instrumental. En una acción instrumental de gestión educativa como la planificación escolar provincial, el discurso y el saber serían equivalentes a los anteriores y variaría la referencia teórica, que en este caso sería una teoría de la organización. La racionalidad es de tipo instrumental y su manifestación podría ser la elaboración del mapa escolar de la provincia.

\begin{tabular}{|c|c|c|c|c|}
\hline $\begin{array}{l}\text { Tipos de ac- } \\
\text { ción }\end{array}$ & $\begin{array}{l}\text { Tipo de saber } \\
\text { materializado }\end{array}$ & $\begin{array}{l}\text { Forma de ar- } \\
\text { gumen- } \\
\text { tación }\end{array}$ & $\begin{array}{l}\text { Modelo de } \\
\text { racionalidad }\end{array}$ & $\begin{array}{l}\text { Manifestación } \\
\text { en la Institu- } \\
\text { ción Escolar }\end{array}$ \\
\hline $\begin{array}{l}\text { Acción estraté- } \\
\text { gico instrumen- } \\
\text { tal }\end{array}$ & $\begin{array}{l}\text { Saber en forma } \\
\text { de técnicas y } \\
\text { estrategias }\end{array}$ & $\begin{array}{l}\text { Discurso teó- } \\
\text { rico }\end{array}$ & Instrumental & $\begin{array}{l}\text { Técnicas, estra- } \\
\text { tegias, enseñan- } \\
\text { za técnica }\end{array}$ \\
\hline $\begin{array}{l}\text { Acción comu- } \\
\text { nicativa (ver- } \\
\text { dad) }\end{array}$ & $\begin{array}{l}\text { Saber teórico } \\
\text { empírico }\end{array}$ & $\begin{array}{l}\text { Discurso } \\
\text { Teórico }\end{array}$ & Comunicativa & $\begin{array}{l}\text { Teorías, princi- } \\
\text { pios educativos. } \\
\text { Proyecto Curri- } \\
\text { cular }\end{array}$ \\
\hline $\begin{array}{l}\text { Acción comu- } \\
\text { nicativa (nor- } \\
\text { matividad) }\end{array}$ & $\begin{array}{l}\text { Saber práctico } \\
\text { moral }\end{array}$ & $\begin{array}{l}\text { Discurso } \\
\text { práctico }\end{array}$ & Comunicativa & $\begin{array}{l}\text { Normas. Regla- } \\
\text { mento de Régi- } \\
\text { men Interno }\end{array}$ \\
\hline $\begin{array}{l}\text { Acción comu- } \\
\text { nicativa (vera- } \\
\text { cidad) }\end{array}$ & $\begin{array}{l}\text { Saber práctico } \\
\text { axiológico }\end{array}$ & $\begin{array}{l}\text { Crítica ideo- } \\
\text { lógica }\end{array}$ & Comunicativa & $\begin{array}{l}\text { Proyecto Edu- } \\
\text { cativo }\end{array}$ \\
\hline $\begin{array}{l}\text { Acción potencial- } \\
\text { mente comunica- } \\
\text { tiva o educativa } \\
\text { (verdad) }\end{array}$ & $\begin{array}{l}\text { Saber teórico } \\
\text { empírico }\end{array}$ & $\begin{array}{l}\text { Discurso teó- } \\
\text { rico }\end{array}$ & Comunicativa & $\begin{array}{l}\text { Procesos de en- } \\
\text { señanza-apren } \\
\text { dizaje instructi- } \\
\text { vos }\end{array}$ \\
\hline $\begin{array}{l}\text { Acción poten- } \\
\text { cialmente co- } \\
\text { municativa o } \\
\text { educativa (nor- } \\
\text { matividad) }\end{array}$ & $\begin{array}{l}\text { Saber práctico- } \\
\text { moral }\end{array}$ & $\begin{array}{l}\text { Discurso } \\
\text { práctico }\end{array}$ & Comunicativa & $\begin{array}{l}\text { Procesos educa- } \\
\text { tivos formativos } \\
\text { (en cuestiones } \\
\text { práctico mora- } \\
\text { les) }\end{array}$ \\
\hline $\begin{array}{l}\text { Acción poten- } \\
\text { cialmente co- } \\
\text { municativa o } \\
\text { educativa (ve- } \\
\text { racidad) }\end{array}$ & $\begin{array}{l}\text { Saber práctico- } \\
\text { axiológico }\end{array}$ & $\begin{array}{l}\text { Crítica ideo- } \\
\text { lógica }\end{array}$ & Comunicativa & $\begin{array}{l}\text { Procesos edu- } \\
\text { cativos críticos } \\
\text { (aplicación crí- } \\
\text { tico ideológica) }\end{array}$ \\
\hline
\end{tabular}

Figura 7. Formas de racionalidad en las acciones escolares 
Por discurso práctico entendemos aquellas interpretaciones, explicaciones, afirmaciones y justificaciones, orientadas a «aclarar la validez de recomendaciones ( $o$ advertencias), que se refieren a la aceptación (o rechazo) de estándares» (Habermas, 1989, p. 102), es decir, a razonar argumentadamente la validez o no de unas normas, o de una conducta valorada según normas legítimas, es decir, aceptadas intersubjetivamente como válidas. Esta validez vendrá determinada por la aceptación común de que tales normas respaldan realmente las necesidades de todos.

En el gráfico (Fig. 7) se señala que tanto la acción estratégico-instrumental como la acción comunicativa o potencialmente comunicativa (educativa) pueden hacer uso de formas de argumentación de carácter teórico. En el caso de las primeras acciones ya ha quedado expuesta su conexión. En las acciones comunicativas, entre adultos, esta forma de discurso teórico se utiliza cuando el objeto de la comunicación es un hecho, o estado de cosas, que pertenece al mundo objetivo -o bien al mundo social o psíquico objetivado-. Este sería el caso de una reunión de profesores donde se debaten cuestiones metodológicas y su aplicación en el aula, con referencia a los principios teóricos del aprendizaje y sociales que fundamentan sus decisiones. Si las interacciones que se entablan son comunicativas realmente, los que allí se planteen serán argumentos de carácter empírico y teórico que avalen una decisión u otra. El tipo de discurso será el teórico, el saber allí materializado será de carácter teórico-empírico y la racionalidad rectora de tales acciones será comunicativa. La manifestación de tales acciones comunicativas centradas en la pretensión de validez de «verdad» puede ser la concreción de algunos aspectos del Proyecto Curricular del Centro (adopción de criterios de secuenciación de contenidos, o de principios psicológicos del aprendizaje), o simplemente la modificación de principios teóricos de carácter educativo que han sido criticados.

En este mismo supuesto, si el tema que se debate en la reunión de profesores se refiere a cuestiones de disciplina o de valores morales o formativos de los alumnos, entonces el saber allí materializado será de carácter práctico-moral, y los argumentos utilizados para cuestionar o fundamentar la pretensión de validez de normatividad (o rectitud), deberán ser discursos prácticos. Las manifestaciones de tales acciones pueden ser las decisiones en torno al orden que debe regir en el aula o en el centro, o en torno a cuestiones como la de cómo corregir una conducta inadecuada en un alumno, etc. La elaboración del Reglamento de Régimen Interno, en el que participan profesores, padres y alumnos ${ }^{3}$ es también una evidente manifestación de estas acciones. La racionalidad en estos casos será comunicativa.

Si el tema sobre el que se debate en esta reunión de profesores hace referencia a valores personales acerca del concepto de educación o de currículo, o cómo deben ser un buen alumno y un buen profesor, o cuál ha de ser la sociedad que las futuras generaciones deberán construir, etc., entonces el saber que allí se materializa tiene un carácter práctico-axiológico. La pretensión de validez a la que habrá de responder el hablante será la de veracidad y sus argumentos no tendrán la misma naturaleza que en los casos anteriores, ya que la sinceridad no puede demostrarse mediante referencias a teorías o a

34. La participación de los alumnos ha de tener siempre presente las restricciones que les impone su desarrollo madurativo, lo que les impide estar en situación simétrica con los adultos en el proceso de entendimiento. Por este motivo su acción será sólo potencialmente comunicativa (y por tanto su participación en tales procesos de entendimiento será educativa). 
normas legítimas. El discurso estará basado en explicaciones y descripciones vivenciales (opiniones, juicios de valor, sentimientos) y la validez de tales expresiones vendrá dada por la coherencia de las acciones con las emisiones o con manifestaciones anteriores. Aquí se tratará de desvelar los posibles autoengaños que se pueden producir, por lo que el discurso adoptará la forma de crítica ideológica, con referencia a unos teoremas críticos que permitan descubrir el autoengaño o falsa conciencia. El modelo de racionalidad será comunicativo. Las manifestaciones de estas acciones pueden darse tanto en discursos crítico-ideológicos ${ }^{3}$ que se generen en las reuniones de elaboración del Proyecto Educativo del Centro donde han de quedar reflejados los valores educativos y sociales prioritarios en los procesos formativos del Centro. Esta pretensión de validez que caracteriza a los discursos de crítica ideológica está muy relacionada con los discursos prácticos que se producen al tematizar un aspecto práctico-moral de la escuela, lo que permite que los aspectos normativos de las acciones sean también sometidos a crítica ideológica. Considerar que en la práctica comunicativa se produce una separación radical entre los diferentes aspectos de validez del discurso sería falso, pues como señala Habermas este tipo de discursos suelen darse entreligados, ya que cuando hablamos nos referimos de forma indistinta al mundo objetivo, al mundo social o al mundo subjetivo, y nuestras conversaciones suelen tener un carácter mixto o diversificado.

En el caso de las acciones potencialmente comunicativas o educativas, se repite el mismo esquema de las acciones comunicativas, variando las manifestaciones de las mismas al tratarse de interacciones entre adultos y niños o adolescentes (profesores/padresalumnos). Así en los procesos de enseñanza en los que se aborden cuestiones referidas a conceptos, principios, leyes, procedimientos cognitivos, etc., se utilizará un saber teórico-empírico, y los discursos tendrán un carácter teórico. La racionalidad será siempre comunicativa y la manifestación puede ser el aprendizaje/cuestionamiento crítico de contenidos referidos al mundo objetivo (o social y personal objetivado). Cuando se aborden cuestiones referidas a aspectos sociales de carácter normativo, el saber empleado será práctico-moral y los discursos serán prácticos. Las manifestaciones pueden ser tanto la elaboración en asamblea de las normas de convivencia para la clase, como el análisis crítico ideológico de valores sociales sobre los que se fundamentan las leyes. Cuando se aborden directamente cuestiones referidas a valores, como la enseñanza de la solidaridad o la crítica a valores como el de la competitividad o el egoísmo, el saber utilizado será de carácter práctico-axiológico y el discurso, crítico-ideológico. Sus manifestaciones también serán diversas como el análisis críticos de comportamientos insolidarios en el grupo, incoherentes con manifestaciones de solidaridad hechas en otras ocasiones, o bien el análisis crítico-ideológico de formas de vida sociales internalizadas en los alumnos, como la forma de relacionarse interpersonalmente, la desigualdad entre los sexos, la discriminación racial-económica, el hecho de que existan injusticias distributivas en la sociedad o las condiciones laborales abusivas de los trabajadores, etc.

35. Soy consciente de la dificultad que tiene en la práctica el generar discursos de crítica ideológica. Generalmente los profesores no quieren entrar en semejantes tematizaciones y cuando se logra desarrollar un discurso crítico intersubjetivo, entonces suelen manifestar resistencias muy fuertes para reconocer la propia falsa conciencia. 
Finalmente hay que señalar que las categorías que configuran la tipología de las acciones escolares no son excluyentes fácticamente en las dinámicas que se originan en la Institución Escolar, ya que éstas suelen formar parte de secuencias de acciones de diferente carácter quedando entretejidas en las redes de relaciones interpersonales que se originan en los centros. Esta tipología tiene la pretensión de servir como referencia en el proceso hermenéutico de comprensión e interpretación de la vida de la escuela y, asimismo, ofrecer un criterio de orientación -la acción comunicativa- sobre el que establecer procesos de innovación educativa y cambio sobre una base de racionalidad comunicativa. Estos procesos de cambio forman parte del concepto de Teoría Crítica que fundamenta esta propuesta educativo-crítica. Un conocimiento que no genere tras la crítica un movimiento transformador y emancipador, caería en la misma inhumanidad en que incurre el concepto tradicional de teoría. Pero al hablar de innovación educativa nos estamos refiriendo no sólo a una modificación curricular -metodológica, organizativa, de contenidos, etc.- sino también a una transformación en la filosofía social que subyace a cualquier modelo educativo. El cambio que se propone no está vacío de contenido ${ }^{36}$, sino que pretende la construcción de una sociedad, indeterminada como proyecto concreto, pero que sea capaz de establecer sus formas de vida sobre relaciones comunicativas e interpersonales libres de dominio. Cualquier nueva propuesta educativa debería tener este marco de referencia, tanto para estructurar su praxis, como para fijar sus metas. Este es el punto de conexión entre la teoría-praxis educativa y la política. Una acción educativa que aspire a transformar -desde su posición- las estructuras y condiciones sociales de dominio.

Por otra parte soy consciente de que en las dinámicas de la Institución Escolar existen numerosas acciones que no pueden ser clasificadas como racionales, ni desde el punto de vista instrumental ni comunicativo. Los componentes irracionales de la actuación de sus miembros no quedan recogidos en este planteamiento (conflictos sentimentales, dependencias, adhesiones irreflexivas,...), pero esto no supone que el concepto de razón comunicativa deje fuera los sentimientos o las acciones expresivas de los agentes de la acción. Por el contrario no sólo los considera como una de las pretensiones de validez del discurso sino que además los sitúa en el mismo nivel de racionalidad en que puedan ser considerados los hechos intersubjetivamente compartidos. Al dar razón con veracidad de nuestras vivencias intrapsíquicas estamos colocando estas experiencias en el plano de la intersubjetividad que es donde realmente cobran validez.

Regresando a la cuestión que abría este comentario, la respuesta ha quedado justificada a lo largo del mismo. Cuando la Institución Escolar se apoye en criterios de razón comunicativa procurando orientar las acciones de sus miembros hacia acciones comunicativas, estará contribuyendo de forma activa en la construcción de sociedades más humanas, más libres y, en consecuencia, más racionales.

De todas formas esta propuesta, en coherencia con el concepto de Teoría Crítica, queda abierta a la contrastación y a la crítica, de manera que puedan ir superándose las limitaciones que pueda ofrecer.

36. En muchas ocasiones los términos «innovación educativa» o «cambio» son utilizados ideológicamente, ya que son presentados en la literatura pedagógica sin explicitar cuáles son sus criterios de referencia, es decir: cambio ¿hacia dónde?, ¿para qué? En este artículo deseo evitar, al menos en lo posible, cualquier contaminación ideológica del lenguaje. Mi horizonte utópico viene señalado por la Teoría Crítica. 


\section{BIBLIOGRAFÍA}

Austin, J. L. (1982). Cómo hacer cosas con palabras. Barcelona, Paidós.

Benjamín, W. (1991). Para una crítica de la violencia y otros ensayos. Madrid, Taurus.

DANTO, A. C. (1989). Historia y narración. Ensayos de filosofía analítica de la historia. Barcelona, Paidós / ICE-UAB.

Gimeno Lorente, P. (1993). De la Teoría Crítica de la Sociedad a la Teoría Crítica de la Educación. Tesis doctoral (inédita), U.N.E.D., Facultad de Educación.

HABERMAS, J. (1969). Protestebewegung und Hochschulereform. Frankfurt, Suhrkamp Verlag.

HABERMAS, J. (1985). La reconstrucción del materialismo histórico. Madrid, Taurus.

HABERMAS, J. (1987a). Teoría de la Acción Comunicativa. Racionalidad de la acción y racionalización social. vol. 1, Madrid, Taurus.

Habermas, J. (1987a). Teoría de la Acción Comunicativa. Crítica de la razón funcionalista. vol. 2, Madrid, Taurus.

Habermas, J. (1987b). Teoría y Praxis. Madrid, Tecnos.

Habermas, J. (1989). La Teoría de la Acción Comunicativa: Complementos y estudios previos. Madrid, Cátedra.

HABERMAS; DOBERT; NunNER-WinCKLER (1975). Adoleszenzkrise und Identitätbilding. Frankfurt.

Habermas; Friederburg; OeHLER; WeTz (1961). Studenten und Politik. Neuwied.

Hernández Pedrero, V. (1988). «¿Aprenden las sociedades? Premisas psicoevolutivas y sociológicas de la ética comunicativa de Habermas» en Témpora, 11-12, pp. 47-57.

MIEDEMA, S. (1987). «Pädagogik an der Nahtstelle zwischen System und Lebenswelt» en Pädagogische Rundschau, 6, pp. 747-757.

SCHALlER, K. (1987). Pädagogik der Kommunikation. Annäherungen. Erprobungen. Sankt Augustin, Verlag Hans Richarz.

Weber, M. (1944). Economía y sociedad. Mexico, Fondo de Cultura Económica. 